\title{
Parental Characteristics, Supply of Schools, and Child School-enrolment in Pakistan
}

\author{
NadeEm A. BurReY and Mohammad Irfan
}

\begin{abstract}
In recent years, due to a virtual unanimity about the critical role of human capital in economic development, increased efforts are being made in the developing countries to eradicate illiteracy. Despite a significant increase over time in the number of educational institutions and the government's expenditure on education in Pakistan, the performance of the education sector in terms of output has been at best meagre. This non-correspondence between the growth in the educational institutions and the resultant output implies that failure to enlist the participation of the population in education can hardly be attributed exclusively to an insufficiency of the schools. To the extent that child schooling reflects parental capacity to invest in human capital formation, there is a need to reckon with factors bearing parental decision regarding child schooling.

This paper investigates family's decision regarding child schooling through an assessment of the determinants of child school-enrolment, using choice theoretic framework. The regression results are indicative of the influence of household status, both economic and social, on the propensity to invest in child schooling. A positive association between the household income, parental education, and tenurial status as land-owner bear out the importance of these factors in shaping the household's decision regarding investment in human capital formation. The study also finds traces of the quantity-quality trade-off in family's preferences regarding the number of children, and it is found to be male-specific. The most disturbing finding of the study appears to be the predominance of the influence originating from parental education. It is this inter-generational transfer of human capital which needs more attention as it also implies that illiteracy, and hence poverty, of the parents gets transmitted to the off-spring. The analysis also brings out the fact that the labour market hiring practices serve as an important feedback to the household's human capital formation behaviour.
\end{abstract}

\section{INTRODUCTION}

The strategic importance of Human Capital for socio-economic development of a nation hardly needs to be emphasized. The recognition that human resource development should be accorded a paramount importance has been manifest in the educational

Nadeem A. Bumey and Mohammad Irfan are both Chief of Research in the Pakistan Institute of Development Economics, Islamabad.

Authors' Note: We would like to express our gratitude to Professor Syed Nawab Haider Naqvi, Director, Pakistan Institute of Development Economics, for his constant encouragement. The helpful comments made by an anonymous referee of the joumal, and by Ashfaque H. Khan and A.R. Kemal on earlier drafts of the paper, are gratefully acknowledged. We are also thankful to Masood Ishfaq Ahmed for his valuable assistance in programming and preparing the data tapes. We alone are responsible for any remaining errors. 
policies of the developing world. To a certain extent, the development efforts in Pakistan also reflect such a concern. There has been a significant increase over time both in the government's expenditure on education and in the number of educational institutions over the modest base inherited at the time of independence in 1947. In real terms, between 1959-60 and 1984-85, the expenditure on education in Pakistan increased at an average compound growth rate of 9.6 percent. 1 The number of educational institutions increased from 11099 in $1947-48$ to 100243 in 1988-89, i.e., a more than 9-fold increase. ${ }^{2}$

The performance of the education sector in terms of output, however, appears to be meagre in comparison to the expansion in the facilities. For instance, as compared to the more than 9-fold increase in the number of schools, the increase in school enrolment between 1951 and 1981 was only 3.75 times. Currently, the literacy level in Pakistan is one of the lowest in the world. According to the 1981 population census, 26 percent of the total population of Pakistan is literate. Given that the literacy rate in 1951 was only 13 percent, and that many other countries were able to achieve much higher literacy levels in a relatively shorter period, the improvement in Pakistan's literacy rate can at best be termed as modest. Furthermore, the school enrolment ratios are hardly enviable. In 1981, out of the total population in the age cohort of 10-24 years, 17.6 percent was enrolled in the schools compared to only 11.8 percent in 1961. Notwithstanding the policy intent of universalization of primary education, only a fraction of the population in the relevant age group is enrolled in the educational institutions.

In addition to the overall low literacy rate and school enrolment ratio, large differentials exist between the performance of the urban and the rural sectors and by sex within each sector. The enrolment ratios reported in Table 1 indicate that not only the enrolment ratio in the rural sector has remained far below that in the urban sector, but that the differential has increased over time. Furthermore, within each sector, the female enrolment ratio has remained substantially lower as compared to the male enrolment ratio. However, while in the urban sector, the differential in the male-female enrolment ratios has somewhat narrowed over time, it has widened in the rural sector. The literacy rates by the urban-rural and the male-female classifications reported in Appendix Table 1 further highlight the fact that the literacy rates exhibit a similar pattern and have followed the same trend as the enrolment ratios.

The non-correspondence between the growth in the educational institutions and the resultant output implies that failure to enlist the participation of the population in

${ }^{1}$ In nominal terms, the expenditure on education increased frmm Rs 30.4 million in 1947-48 to Rs 21425 million in 1988-89. Around 70 percent of the expenditure on education has been non-development, and the rest has been development. As a percentage of the GNP, however, the expenditure on education has remained modest, e.g., in 1987-88 it was only 2.4 percent compared to 0.9 percent in 1959-60.

${ }^{2}$ The sharpest increase came in the number of Colleges followed by High Schools, Universities, Primary Schools, Professional Colleges, and Middle Schools - in that order. The increase in the number of such institutions for females, across almost all the categories, was considerably higher than the national average increases. 


\section{Table 1}

School Enrolment Ratio of Population, 10 -24 Years of Age in Pakistan, by Sector and Sex

Sex/Years

Sectors
Both Sexes

\begin{tabular}{|c|c|c|c|c|c|c|c|}
\hline \multirow[b]{2}{*}{ Sectors } & \multirow[t]{2}{*}{ Sex/Years } & \multicolumn{2}{|c|}{ Both Sexes } & \multicolumn{2}{|c|}{ Male } & \multicolumn{2}{|c|}{ Female } \\
\hline & & 1961 & 1981 & 1961 & 1981 & 1961 & 1981 \\
\hline Overall & & 11.8 & 17.6 & 17.0 & 22.9 & 5.7 & 11.5 \\
\hline Urban & & 21.6 & 31.3 & 26.3 & 34.6 & 15.7 & 27.5 \\
\hline Rural & & 8.1 & 11.4 & 13.3 & 17.6 & 2.2 & 4.3 \\
\hline
\end{tabular}

\begin{tabular}{|c|c|c|c|c|c|c|c|}
\hline \multirow[b]{2}{*}{ Sectors } & \multirow[t]{2}{*}{ Sex/Years } & \multicolumn{2}{|c|}{ Both Sexes } & \multicolumn{2}{|c|}{ Male } & \multicolumn{2}{|c|}{ Female } \\
\hline & & 1961 & 1981 & 1961 & 1981 & 1961 & 1981 \\
\hline Overall & & 11.8 & 17.6 & 17.0 & 22.9 & 5.7 & 11.5 \\
\hline Urban & & 21.6 & 31.3 & 26.3 & 34.6 & 15.7 & 27.5 \\
\hline Rural & & 8.1 & 11.4 & 13.3 & 17.6 & 2.2 & 4.3 \\
\hline
\end{tabular}

\begin{tabular}{|c|c|c|c|c|c|c|c|}
\hline \multirow[b]{2}{*}{ Sectors } & \multirow[t]{2}{*}{ Sex/Years } & \multicolumn{2}{|c|}{ Both Sexes } & \multicolumn{2}{|c|}{ Male } & \multicolumn{2}{|c|}{ Female } \\
\hline & & 1961 & 1981 & 1961 & 1981 & 1961 & 1981 \\
\hline Overall & & 11.8 & 17.6 & 17.0 & 22.9 & 5.7 & 11.5 \\
\hline Urban & & 21.6 & 31.3 & 26.3 & 34.6 & 15.7 & 27.5 \\
\hline Rural & & 8.1 & 11.4 & 13.3 & 17.6 & 2.2 & 4.3 \\
\hline
\end{tabular}

Female

Source: Population Census 1961 and 1981.

education can hardly be attributed exclusively to an insufficiency of schools. The education system may possibly be suffering from problems of inadequacy and incfficiency in certain respects. As for the observed urban-rural and male-female differentials in the literacy and school enrolment, one might be tempted to attribute them to differentials in the availability/access to the schools. But this would be a simple treatment of a complex situation. Similarly, one cannot single out culture as the sole factor influencing female enrolment. Enrolment differentials are also influenced by the parental characteristics and socio-economic status of the household. Mason (1988) and Irfan (1985) in their studies on the determinants of child school enrolment, in Thailand and the rural areas of Pakistan, respectively, have highlighted the importance of such factors. $^{3}$

To the extent that child schooling reflects the parental capacity to invest in human capital formation, there is a need to reckon with the factors bearing upon the parental decision regarding child schooling. It is likely that factors operating on the demand side may have a role in explaining low school enrolment and large urban-rural and malefemale differentials in school enrolment ratios. Identification of the factors underlying the meagre performance of the education sector is imperative for policy formulation. This exercise aims to investigate the family's decision regarding child schooling through an assessment of the determinants of child school enrolment, using choice theoretic framework. The study examines the impact of the household income, household size, ownership of assets, parents' education, and other socio-economic factors on the

${ }^{3}$ See also Waite, DeTray and Rindfuss (1983) on the importance of the mother's background in influencing expectation about their children's educational attainments. 
schooling of an individual child. In so doing, an explanation is provided of the inter- and intra-family differences in educational investment, by sector, sex, and age cohorts.

The rest of the paper is organized as follows: Section II presents the specifications of a model of child schooling. Section III discusses data sources. The estimation technique of the model is briefly discussed in Section IV. Section V is devoted to a discussion of the results. The final section provides the principal findings and policy recommendations.

\section{A MODEL OF CHILD SCHOOLING}

The parents' decision to educate their children, or invest in human capital formation, has often been analyzed in a Chicago-Columbia framework, ${ }^{4}$ where the demand for schooling is determined jointly with the number of children. ${ }^{5}$ Both the quantity and the quality of children are assumed to enter the family's utility function. Under this framework, parents in their utility maximizing decisions regarding the family size, investment in child's quality, and their own consumption, substitute between the quantity and the quality of children, depending upon the relative shadow price of the quantity and the quality of children. The interaction between the quantity and the quality in the full resource constraint means that the shadow price of the quantity depends on the quality, and vice versa. Various empirical exercises have lent support to this quantityquality trade-off [See Lindert (1977); Rosenzweig and Wolpin (1980) and DeTray (1978)]. In this framework, the parents' education and socio-economic status are considered to have a significant impact on child schooling. For example, in many empirical studies, the mother's schooling is found to be positively associated with child schooling. This association is interpreted to reflect the productivity-enhancing impact of schooling in the market and household activities. ${ }^{6}$ Within the Chicago-Columbia framework, much of the work on child schooling has been done in the context of fertility behaviour. A few researchers, however, have also attempted to analyze child schooling per se. The studies by King and Lillard (1983); Mason (1988) and Waite, DeTray and Rindfuss (1983) are some of the examples.

The determinants of child school-enrolment in Pakistan have been examined by Irfan (1985). The study focussed only on the rural areas and investigated the school

${ }^{4}$ For details, the readers are referred to Becker and Lewis (1973); Becker and Tomes (1976) and DeTray (1973).

SIn most empirical studies, child schooling is also widely interpreted to represent child quality. Becker and Tomes (1976), however, have raised serious doubts about this interpretation. See Wolfe and Behman (1983) for an elaborate exposition of the issue. Other factors, which affect child quality, are genetic endowment, investment in child health and nutrition, parental time, etc.

Tn the alternative 'Pennsylvanian' model, this is interpreted to reflect an inter-generational effect rather than the productivity effect of educated parents. This implies that the parents' schooling in the Pennsylvanian model does not have as large a productivity effect as in the Chicago-Columbia framework. 
enrolment of children in 10-14 years of age group. Furthermore, rather than taking the individual child in the family as the unit of observation, the study focussed on the number of school-going children in the family as a proportion of total household members. This amounts to examining inter-family differences in school enrolment which is indirectly assuming that there are no differences in school enrolment across children within each family.

Assuming that child school enrolment is determined by the household's characteristics, the model of child schooling can be described as:

$$
S C H=f(x)
$$$$
\text { ... } \quad \text {... }
$$

where $S C H=1$ if the child goes to school, and 0 otherwise.

The parents' decision to send their children to school is influenced by a number of factors reflecting upon the parents' capacity to educate their children, the cost of schooling, the benefits from schooling, the social status of the parents, the societal norm, etc. The vector ' $x$ ' thus usually includes household income, household size, ownership of assets, parents' education, father's employment status and occupation, availability of school, etc. Household income captures the impact of resource constraint on child schooling, i.e., the income effect. A priori, it is expected to be positively associated with child schooling. ' The coefficient of the household size is expected to reveal whether there exists any trade-off between the child schooling and the larger family size. ${ }^{8}$ The relationship between the ownership of assets and child-schooling cannot be determined a priori. Asset ownership can have at least three different types of effects: a pure wealth effect which is positive; an opportunity cost effect which is negative; and a bequest effect which can be either positive or negative. ${ }^{9}$ The net effect of these on an individual child's

In the strict Chicago-Columbia tradition, full permanent income is considered to be positively associated with child schooling. Behman and Wolfe (1984), however, have argued that actual household income is a better representative of permanent income if there are important fixed effects. In most household studies, total household expenditures have been used as a proxy for a permanent income. As the coefficients of independent variables are not likely to differ significantly, whether actual income or expenditure is used, we focus on the actual household income only.

${ }^{8}$ As our analysis will be restricted to nuclear family households, a larger family implies more children. If child schooling is taken as a proxy of child quality, then the sign of the coefficient of the household size would also indicate whether there is any trade-off between the quantity and the quality of children.

'The impact of the increase in the quantity of the household's assets on the parents' decision to educate their children is taken as the 'pure wealth effect' of asset ownership. By increasing the permanent (expected) income of the household, the increase in the quantity of assets favourably influences the parents' decision regarding their children's schooling. The impact of the increase in the value of assets, on the other hand, is taken as the 'opportunity cost effect' of asset ownership on child schooling. An increase in the value of assets, by raising the opportunity cost of the child's time as well as the family's wealth, adversely affects the school enrolment of the children. The impact of a possible bequest by the parents on child schooling is taken as the 'bequest effect' of asset ownership. Since one of the objectives of investing in child schooling is insuring better earnings in the future, parents with more wealth may invest less in the schooling of their children, knowing that the children will inherit their wealth and, hence, such investment is not income-increasing. 
schooling depends on the relative implicit price of schooling among siblings and on the sibling order which produces the bequest effect. [See also King and Lillard (1983)].

Parents' schooling reflects the taste and the capacity of parents to supervise child schooling. As more educated parents are more efficient per unit of time and other inputs in the training of children, their educational attainments by reducing the cost of schooling the child are expected to be positively associated with child schooling. The coefficients of the parents' education also reflect upon the inter-generational transmission of educational attainment.

In both the Chicago-Columbia and the Pennsylvanian frameworks, other factors, besides the household's income, family size, ownership of assets, and parents' education, are also likely to affect the parent's decision to educate their children. In this context, the household's socio-economic status is considered to have an important influence. ${ }^{10}$ For instance, for given income and educational qualifications, households belonging to low status group face a totally different set of opportunities. This is because labour market hiring procedures discriminate against them. ${ }^{11}$ A priori ascertainment of the impact of the household's social status - determined to a large extent by the employment/tenurial status and occupation of the household head (father) - on child schooling, whether positive or negative, cannot be made.

It is generally believed that the neighbourhood in which a household lives has considerable influence on its expenditure pattern. For instance, a household living in a relatively rich neighbourhood is likely to be spending a relatively larger proportion of its income on consumer durables compared to a household living in a poor neighbourhood. ${ }^{12}$ Such a phenomenon, referred to as the 'Demonstration Effect' or the 'Duesenberry Effect', is also usually observed in the context of the family's decisions to educate their children. Households belonging to areas with a relatively more literate population generally exhibit a higher level of human capital formation, perhaps due to the demonstration effect. Thus, area literacy level reflecting the societal norms regarding literacy is included in order to test the existence or otherwise of the demonstration effect. The availability of a school in the area, which accounts for the cost of a school, is likely to be positively related to the child's school enrolment.

\section{THE DATA}

The analysis in this paper will be based on the household level micro data from the Population, Labour Force and Migration (PLM) Survey undertaken by the Pakistan

\footnotetext{
${ }^{19}$ Socio-economic status can also be taken as a measure of the parents' background, which is given considerable importance in the Pennsylvanian framework.

${ }^{11} \mathrm{Khan}$ and Irfan (1985) have found that wage income of the secondary eamer is positively influenced by the parental status even after controlling the human capital variables of the secondary eamers.

${ }^{12}$ For a more systematic treatment of such a phenomenon, see Duesenberry (1952).
} 
Institute of Development Economics (PIDE) in collaboration with the ILO and UNFPA in 1979. The survey, based on a national sample, covered 10288 households and generated data on the households' decision-making process concerning four different aspects, viz., fertility, migration, labour force participation, and income and expenditure. As in Pakistan and many other developing countries extended or joint families are common particularly in the rural areas, the parents' choice regarding the schooling of their children is unlikely to be clearly established where the households are headed by someone other than the parents. Thus, in order to focus sharply on the parents' decision to educate their children, we restrict our analysis to the nuclear family households. ${ }^{13}$

The PLM data on the educational attainment or school enrolment pertains to the information on the level of education of each person in the household. The current enrolment in schools, however, is available only for the household members aged 10 years and above. This latter information is obtained in response to the question on "reason for not working". As the focus of our analysis is the schooling of individual child in the family, the dependent variable, i.e., $S C H$, takes the value " 1 " if the reason for the child's not working is stated to be 'engaged in studies'. In all other cases, the dependent variable takes the value ' 0 '. As in Pakistan the school enrolment in the urban and the rural sectors are different, which can be partly attributed to the difference in their respective labour markets, the analysis will be carried out separately for the urban and the rural households. In addition, since the parents' propensity and capacity to educate their children is expected to be influenced by the age and the sex of the child-as the opportunity cost of schooling increases with age and the returns to schooling are lower for females because they have lower rates of labour force participation -, children of each sex are categorized into four age groups: (i) $10-14$ years old, (ii) $10-16$ years old, (iii) 17 - 20 years old, and (iv) 21 - 25 years old. ${ }^{14}$ An alternative to running separate regressions by sector, sex, and age of the child would be to run a single regression with appropriate dummies as independent variables which take an account of the above factors. A sufficient number of observations in different age/sex categories for each sector are available but since the introduction of too many dummies in the regression complicates measuring properly the interaction and cross-interaction among the different

${ }^{13}$ It may be pointed out that this does not, in any significant way, affect the conclusions of this study because even in a joint family system, the decision to educate a child is generally taken by the parents rather than the household head. Among the households included in the sample, 59 percent of the urban and 61 percent of the rural households are reported to be nuclear families.

${ }^{14}$ Most of the children falling in the 10-16 years age group are expected to be attending the middle (class VI-VIII) and secondary (class IX and X) schools. A small fraction, however, may be enrolled in primary classes. Children falling in the $17-20$ years, and $21-25$ years of age group, respectively, are likely to be attending colleges and universities. Separate regression for children in 10-14 years of age group is estimated because this is one of the categories for which the data on literacy and school enrolment are reported in the Population Census Reports. As such, the separate estimates can be used for comparison with the overall macro situation. 
variables and dummies, a separate regression for each category is estimated. The current school enrolment of children in different age groups, by sector and sex, as observed in the data, is given in Table $2 .^{15}$

The evidence given in the table indicates that around 45 percent of the children in the $10-14$ years age group attend school. ${ }^{16}$ In the case of children in $17-20$ years and $21-25$ years age groups, these numbers are around 18 percent and 5 percent, respectively. For each age group, the differences in the school enrolment, across sectors and within each sector across children of different sex, are interesting to note. While 65 percent of the children in $10-14$ years age group in the urban sector attend school, the enrolment in the rural sector is only 31 percent. A similar pattern appears for the other age groups. Within each sector, large differences exist between the school enrolment of male and female children, with the male enrolment being higher.

Besides information on the household composition, the survey contains data on household income, expenditure, and saving. The survey, however, is deficient in data on asset ownership. As no information on asset ownership is available for the urban households, the impact of wealth on child schooling cannot be examined. In the case of the rural households, however, the households' land-holding will be used as a proxy for the wealth. A particular rural household is termed as a landless household if the usual occupation of the household-head is reported to be agricultural labour without any land. The impact of the parents' education on child schooling will be analyzed by defining various dummies for different educational levels of both the fathers and the mothers, separately. This is because while father's education is more likely to have an indirect effect via income, mother's education has more direct role in training. The impact of the household's social status will be examined by taking into consideration father's employment/tenurial status and occupation.

In addition, the impact of the household's labour force participation behaviour on child schooling is also examined by considering the proportion of household members reported to be engaged in labour force activities. This is primarily for the reason that for households registering a high labour force participation the opportunity cost of sending children to schools is relatively high. As literacy level of the urban area was not available in the data tape, the impact of the societal norm in the context of literacy level will be examined only for the rural households by using the village literacy rate. The impact of the availability of a school will be analysed only for the rural areas by defining different dummies for the presence of a school in the village. The description of all the explanatory

${ }^{15}$ See also Rosenzweig (1978); Birdsall (1980) and Harrison (1980) for an analysis of age- and sexspecific school enrolment of children.

${ }^{16}$ It must be mentioned that, as compared to Population Census 1981, the school attendance reported in the PLM Survey appears to be on the high side. It is difficult to determine whether the PLM data reflect an over-reporting or the Population Census underreports the school enrolment. The discrepancy between the two sources merits further investigation. 


\section{Table 2}

Current School Enrolment of Children in Different Age Groups, by Sector and Sex

Sectors/Sex

Age Group

$$
\text { 10-14 Years } 10-16 \text { Years 17-20 Years 21-25 Years }
$$

Overall

44.60

41.30

18.10

$\mathbf{5 . 3 0}$

Urban

$\begin{array}{lrrrr}\text { Both Sexes } & 64.60 & 60.40 & 30.60 & 9.70 \\ \text { Male } & 76.30 & 70.90 & 36.60 & 13.80 \\ \text { Female } & 52.00 & 49.30 & 23.20 & 5.90\end{array}$

\section{Rural}

Both Sexes

30.90

27.80

7.60

1.90

Male

37.20

42.90

12.80

3.60

Female

11.70

9.90

1.70

0.70

Source: PLM Survey, 1979.

variables to be used in the regressions for both the urban and the rural sectors, together with their mean values, is given in Table 3.

\section{ESTIMATION TECHNIQUE}

As the dependent variable in our model is binary in nature and takes discrete values 0 and 1 , the ordinary least-square (OLS) method is inappropriate not only because of the problems associated with heteroscedasticity but also because there is nothing to constrain the dependent variable to the unit interval. ${ }^{17}$ The most commonly used methods to examine the behaviour of binary dependent variables by regression analysis are: (i) the Linear Probability Model, (ii) the Probit Model, and (iii) the Logit Model. These models differ from each other in terms of the different cumulative distribution function 


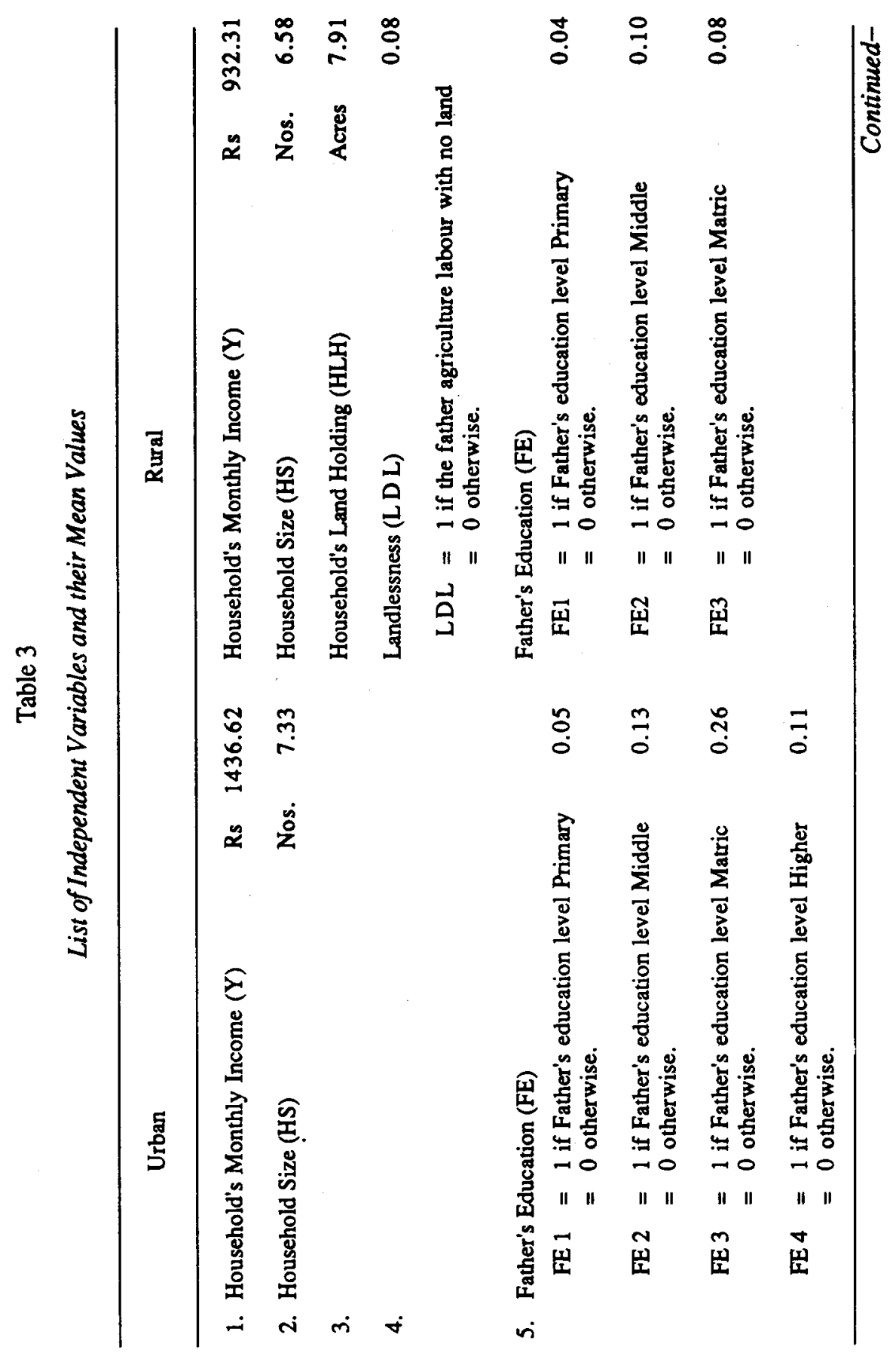


ㅇํㅇ : :

\%

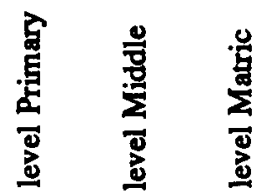

옹 홍 홍

马्马

马ु్

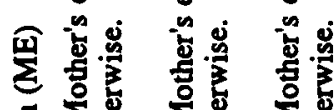

苗

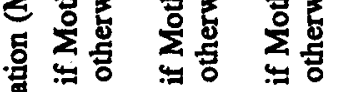

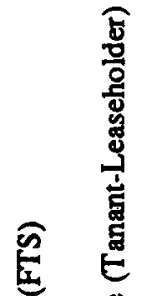

可同

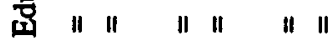

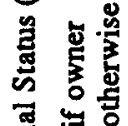

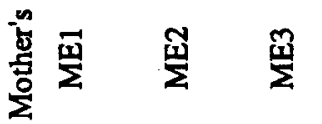

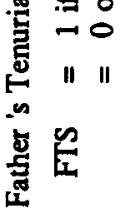

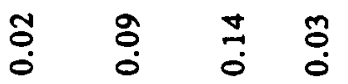

$\stackrel{\forall}{0}$

$\stackrel{0}{0}$

$\stackrel{\infty}{0}$

ติ

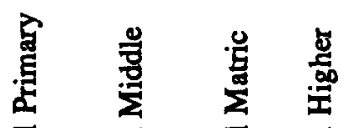

অ

홍

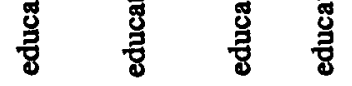

国

政

点

范

苨

ब जू

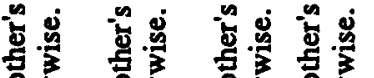

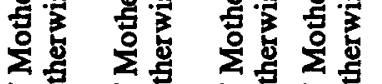

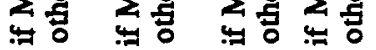

न0 mo mo to

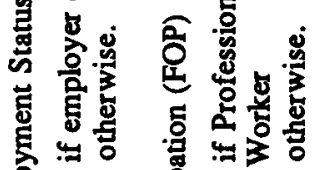

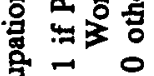

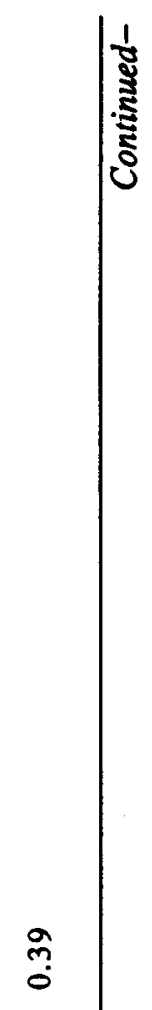

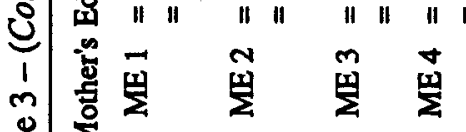

을 $\rightarrow 0$

占 $\mid 1$ I

总

这全

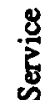

을

몰

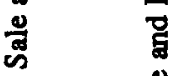

की

0

$\therefore \infty$ 


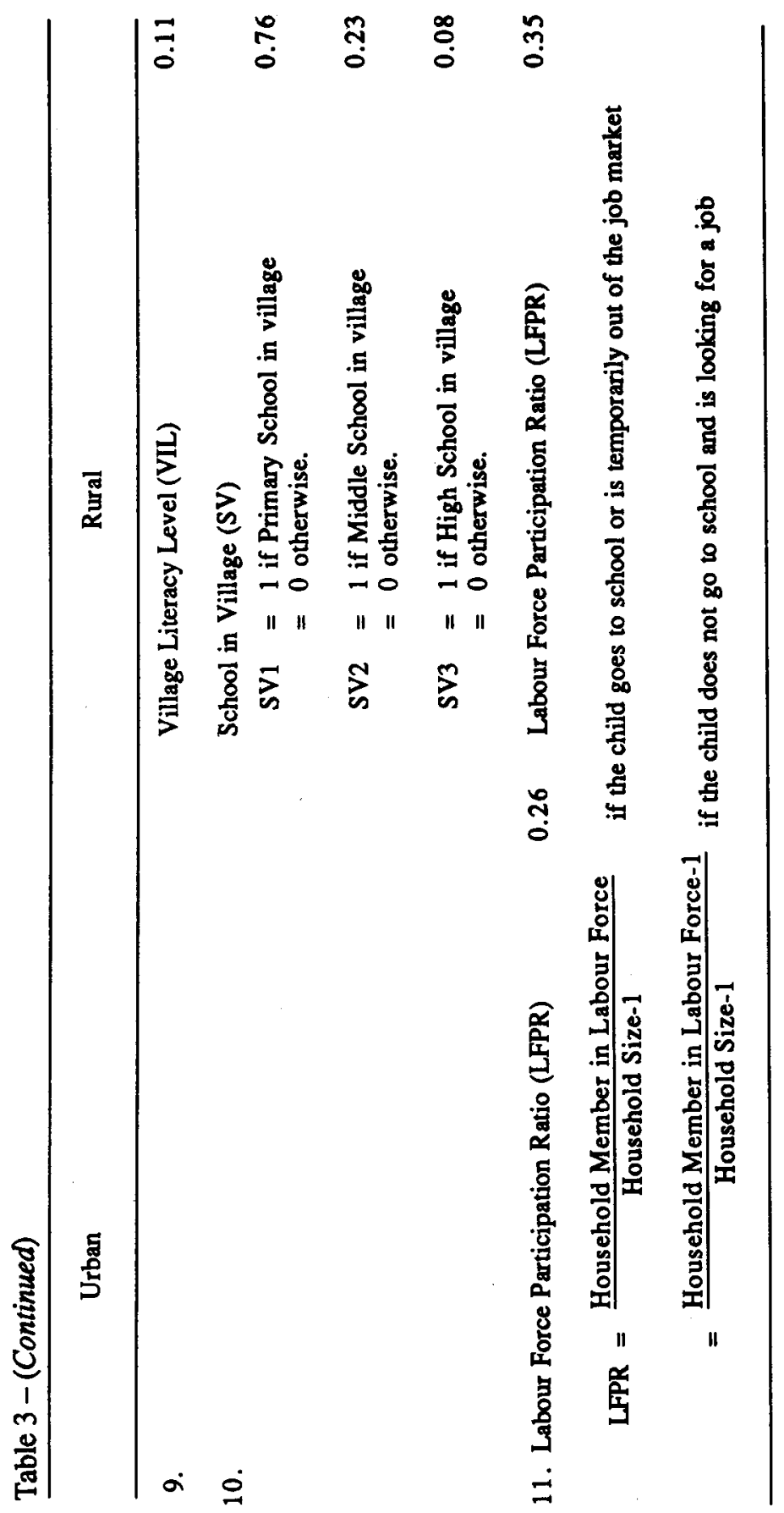


assumed in the regression relationship. ${ }^{18}$

As the conditional probability interpretation of the linear probability model is not always fully satisfied, the non-linear functional forms, e.g., the probit and the logit, are preferred. However, a priori, on theoretical grounds it is difficult to determine which of the two non-linear models is appropriate for any particular problem. In the case of binary variables, however, because normal and logistic distributions are very close to each other except at the tails, the estimates obtained using the probit and the logit forms are likely to be close unless the samples are large. ${ }^{19}$ The estimates, however, are not directly comparable because the variance in the distributions is assumed to be different. ${ }^{20}$

In the standard OLS regression the value of the coefficient represents change in the dependent variable caused by a unit change in the independent variables. In the case of the probit and the logit estimates, the effects of a unit change in an explanatory variable

${ }^{18}$ If $y$ is the binary dependent variable and $x$ a vector of explanatory variables, then each of these models implies that the probability of success, in our case the probability of the child going to school, can be written as:

$$
E(y / x)=p(x)=F\left(x^{\prime} \beta\right)
$$

where $F($.$) is the cumulative distribution function and \beta$ a vector of the parameters to be estimated. The linear probability, the probit and the logit models, respectively, assume that the cumulative distribution function is linear, normal, and logistic, which can be written as:

$$
\begin{array}{ll}
F\left(x^{\prime} \beta\right)=x^{\prime} \beta & \text { Linear } \\
F\left(x^{\prime} \beta\right)=(1 / \sqrt{2 \pi}) \int_{-\infty}^{x \beta}\left(-t^{2} / 2\right) d t & \text { Probit } \\
F\left(x^{\prime} \beta\right)=1 /\left(1+\exp \left(-x^{\prime} \beta\right)\right) & \text { Logit }
\end{array}
$$

For a detailed discussion on each of these models, the reader is referred to Kmenta (1986, ch. 11); Goldfeld and Quandt (1972, ch. 4) and Maddala (1983, ch. 2). The Linear Probability Model has also been termed as the Uniform Model by Goldfeld and Quandt.

${ }^{19}$ For more on this, see, for example, Kmenta (1986) and Maddala (1983). comparable:

${ }^{20}$ Amemiya (1981) has suggested the following transformation to make the coefficients

$$
\begin{array}{lll}
\hat{\beta}_{p} & \simeq 0.625^{*} \hat{\beta}_{L} & \\
\hat{\beta}_{p} & \simeq 2.5^{*} \hat{\beta}_{L P} & \text { (except for constant term) } \\
\hat{\beta}_{p} & \simeq 2.5^{*} \hat{\beta}_{L P}-1.25 & \text { (for the constant term) }
\end{array}
$$

where $\hat{\boldsymbol{\beta}}_{p}, \hat{\boldsymbol{\beta}}_{L}$, and $\hat{\boldsymbol{\beta}}_{L P}$ are probit, logit, and linear probability estimates, respectively. 
on the probability of success depend on the particular value of the vector of explanatory variables. The change in the probabilities given by the linear probability model, the probit model, and the logit model, with respect to the $i$ th explanatory variable, respectively, is as follows:

$\frac{\partial P}{\partial x_{i}}=\frac{\partial F\left(x^{\prime} \beta\right)}{\partial x_{i}}=\beta_{i}$

Linear

$\frac{\partial P}{\partial x_{i}}=\frac{\partial F\left(x^{\prime} \beta\right)}{\partial x_{i}}=F^{\prime}\left(x^{\prime} \beta\right)^{*} \beta_{i}=f\left(x^{\prime} \beta\right)^{*} \beta_{i}$

Probit

$\frac{\partial P}{\partial x_{i}}=\frac{\partial F\left(x^{\circ} \beta\right)}{\partial x_{i}}=F^{\prime}\left(x^{\prime} \beta\right)^{*} \beta_{i}=\frac{\exp \left(x^{\circ} \beta\right)}{\left(1+\exp \left(x^{\prime} \beta\right)\right)^{2}} * \beta_{i}$

where $f\left(x^{\prime} \beta\right)$ is the density of the standard normal distribution function. As is evident, while in the case of linear probability model the effects of changes in the independent variables on the probability of success are constant, for the probit and the logit models they depend on the particular values of the explanatory variables.

As the current school enrolment of children in both the urban and the rural sectors is found to vary by the age and the sex of the child, in this paper we shall estimate separate regressions for each age group by sector and sex. Because, a priori it is difficult to determine which of the three functional forms - viz., linear probability, probit, and logit - is more appropriate for our data, we shall estimate the model using all three functional forms. For comparison, the estimates obtained by using different forms will be adjusted, using the transformation suggested by Amemiya (1981). Finally, the marginal effects of the independent variables on the probability of attending school will be examined.

\section{RESULTS}

In order to highlight the importance of the household's socio-economic status and community variables in accounting for the urban-rural and the male-female differentials in the school enrolment of children in a developing country like Pakistan, the relationship (2.1) was first estimated with household income, family size, and parents' education as the only explanatory variables. The results for each sector by the sex and the age group of the child, obtained by using the linear probability model, the probit model, and the logit model, are presented in Annexure Tables $2-5 .{ }^{21}$ The estimates are consistent,

${ }^{21}$ The linear probability model has been estimated using the OLS method rather than the GLS, i.e., the correction for heteroscedasticity has not been made. Goldfeld and Quandt (1972, ch. 4) have shown that for the linear probability model there appears no appreciable difference between the OLS and the GLS estimates. 
qualitatively, across the alternative forms of the model. ${ }^{22}$ The explanatory variables included in the regressions explain 5 to 32 percent of the variations in the dependent variable, depending upon the sector, sex, and age group of the child.

As the linear probability and the probit and the logit formulations assume different functional forms for the distribution, the coefficients are not directly comparable. For comparison, the linear probability and the logit estimates reported in Annexure Tables 2- 5 were adjusted, using the transformation suggested by Amemiya (1981). The transformed coefficients are reported in Annexure Tables 6 - 9. In general, the linear probability coefficients are the smallest and the logit coefficients are the largest. The difference between the probit and the logit coefficients, however, does not appear to be large. As the other statistics, e.g., $R$-square and $\log$ of likelihood function, for the two models are also close, they suggest that both the probit and the logit functional forms are equally appropriate for our data. Since the OLS method does not yield satisfactory results anyway, only the probit estimates will be used to discuss the effects of different explanatory variables on the school enrolment of children.

The estimates reported in the tables indicate that, in general, all the variables have anticipated signs. The coefficients, however, are not necessarily significant in all the cases. The coefficient of the household income is positive and, except for urban males of upto 20 years of age and urban females of $21-25$ years of age, is significant for other groups. It must be noted that the cross-sectional association between household income and child school-enrolment can hardly be treated as a true relationship because the household income is not adjusted for the contribution of the working child of the same age group. The regression results, therefore, tend to under-estimate the actual effect of income to an unknown extent. Mason (1988) used household expenditure as a proxy for permanent income and found that in Thailand the household's permanent income has a significant positive effect on the school enrolment of children in 15-17 and 18-24 years age groups. Mason, in his study, does not take account of the difference in school enrolment arising due to the household's residence in the urban/rural areas. In addition, separate regressions for males and females are not estimated. However, significant differences in the school enrolment by sex are found to exist.

The sign of the coefficient of the household size points to the non-existence of the trade-off between the quantity and the quality of children in Pakistan. ${ }^{23}$ Not only is the sign of the coefficient, in general, positive, but also it is insignificant except for urban

${ }^{22}$ As very few positive observations for the dependent variable were available in the case of the rural male in the 21-25 years age group and the rural female in the 17-20 years and 21-25 years age groups, the results corresponding to these groups are not being reported.

${ }^{23}$ For a trade-off (between the quantity and the quality of the children) to exist, the coefficient of the household-size should be negative. This follows from the fact that, at a given household income, an increase in household size implies a lower income per capita. If the resource constraint is one of the major factors affecting child schooling, then fewer per capita resources are likely to adversely affect the chances of children attending school. 
females. Blake (1981) has demonstrated the existence of the trade-off between the quantity and the quality of child in the case of the U.S. A. For Thailand, Mason (1988) has found that additional young household members discourage enrolment by increasing the opportunity cost of the time of the potential students. Older members, on the other hand, encourage enrolment by decreasing the opportunity cost of the time of the other household members.

The educational level of the parents is positively associated with child schooling. The coefficients, however, are not significant for all the groups. It is interesting to note that the higher the educational level of the parents, the more likely are the older children to be attending school, as reflected by the size and significance of the coefficients of different educational levels of the parents for children in different age groups. Mason (1988) and King and Lillard (1983) obtained similar results for Thailand and the Philippines, respectively.

To examine the impact of the household's socio-economic status and the community variables on the school enrolment of children in Pakistan, the relationship (2.1) was estimated in the second stage with additional explanatory variables: father's employment/tenurial status, father's occupation, the household's land-holdings, presence of school in the area, area literacy, and the household's labour-force participation pattern. The estimates thus obtained, assuming normal cumulative distribution function, are reported in Annexure Tables 10 and 11. It is evident from the tables that the inclusion of the additional variables not only considerably increased the explanatory power of the regressions but also improved the significance of the coefficients of household income, household size, and parents' education. As expected, however, the magnitude of the coefficients decreased slightly. We now discuss in detail the effects of each explanatory variables on the school enrolment of children separately.

\section{(i) Household Income}

It is to be noted that in the extended regressions the coefficient of the household's income is positive and, except for urban females in the $21-25$ years age group, is significant in all the cases. This suggests that, in general, households with higher income are more likely to educate their children irrespective of child's age and sex. The results reported in Table 4 further suggest that the impact of household income on the school enrolment of children is considerably different between the urban and the rural sectors. Furthermore, within each sector, the impact varies by the age and sex of the child. While the impact on female school enrolment is higher as compared to male enrolment in the urban sector, the reverse is true in the case of the rural sector. This may owe to the peculiar structure of jobs in the rural sector, or the prestige associated with being able to afford not having female family members in the labour market. 
Table 4

Change in the Probability of Child's Attending School for a Rupee Change in the Household Income

Sectors/Sex

Age Group

10-14 Years $10-16$ Years $17-20$ Years $21-25$ Years

Urban

$\begin{array}{llllr}\text { Male } & 0.00005 & 0.00005 & 0.00003 & 0.00003 \\ \text { Female } & 0.00012 & 0.00006 & 0.00005 & -0.00001\end{array}$

Rural

Male $\quad 0.00013 \quad 0.0001 \quad 0.00006$

Female

0.00003

0.00002

\section{(ii) Household Size}

In the extended regressions, the evidence on the quantity-quality trade-off, as simulated by the sign of the coefficient of household size, interestingly emerges to be sex-specific. As provided in the Annexure Tables 10 and 11, the trade-off is visible in the case of males. In the case of females, one does not find such a trade-off in the urban sector. Pending an in-depth investigation, this finding can be explained in terms of the opportunity costs of schooling and the socio-cultural factors. The limited work opportunities for females within or outside the households and the enhancement in the capacity to get a better educated husband through a higher level of schooling may underlie these results. The estimates reported in Table 5 show that the marginal effect of the increase in the household size on the probability of attending school shows different patterns across different age groups in the urban and the rural sectors. Whereas in the urban sector the impact on the probability first rises and then falls for both males and females, in the rural sector it declines for males but rises for females.

Table 5

Change in the Probability of Child's Atlending School for a

Unit Change in the Household Size

\begin{tabular}{ccccc}
\hline & \multicolumn{4}{c}{ Age Group } \\
\cline { 2 - 4 } Sectors/Sex & $10-14$ Years & $10-16$ Year & $17-20$ Years & $21-25$ Years \\
\hline Urban & & & & \\
Male & -0.015 & -0.016 & -0.015 & 0.012 \\
$\quad$ Female & 0.011 & 0.013 & 0.016 & 0.012 \\
Rural & & & & - \\
$\quad \begin{array}{l}\text { Male } \\
\text { Female }\end{array}$ & -0.025 & -0.018 & -0.002 & - \\
\hline
\end{tabular}




\section{(iii) Land-holdings}

Among the rural households, the size of land-holdings is found to be negatively associated with boys' schooling. This suggests that for households with large landholdings, the opportunity cost of sending boys to school tends to dominate the pure wealth effect. ${ }^{24}$ This result is in sharp contrast to the one obtained by King and Lillard (1983) for the Philippines. They have shown that an increase in the household's landholdings increases school enrolment at all the levels. ${ }^{25}$ Boys of 10-16 years of age of a landless household are found to be less likely to be attending school. As landless households are generally engaged as agricultural labour, they are also likely to be lowincome households, where children usually start working at a young age rather than going to school. Our estimates fail to establish any relationship between female schooling and land-ownership.

\section{(iv) Parental Education}

In the extended regressions, except for some minor quantitative changes in the impact of parents' education on the school enrolment of children, the overall pattern appears to be similar to that in the simple regression. The estimates show that the educational level of parents is positively associated with child schooling. The coefficients, however, are not significant in all the cases. It is interesting to note that the higher the educational level of the parents, the more likely are the older children to be attending school. For instance, in the urban sector, primary education of the parents appears inconsequential for boys' schooling. Girls, however, are found to stand a better chance. On the other hand, if the educational level of the parents is Matric and/or Higher, both boys and girls of all ages are likely to be attending school. In the rural sector, however, where literacy norms are relatively lower as compared to those in the urban sector, even primary education of the parents is found to be positively associated with the schooling of the children. These estimates, thus, show that as the educational level of the parents increases, the chances of their children's attending school also increase irrespective of the child's age and sex. In other words, children of Higher-educated parents are likely to be more educated, i.e., educational attainments are transmitted intergenerationally. Table 6 gives the marginal effects of the parents' educational level on the probability of their children's attending school. Although there appears to be no clear pattern across different age groups by sex, yet, in general, the marginal effect of father's educational level appears to be larger as compared with that of mother's corresponding level. This can partly be a reflection of father's role in the household decision-making process. As expected, the effect of higher education, e.g., Matric and Higher, is found

\footnotetext{
${ }^{24}$ It must be noted that household income is controlled in the equation which captures the wealth effect due to land.

${ }^{25}$ The coefficient of the land value is found to be positive and greater for fernales than for males.
} 


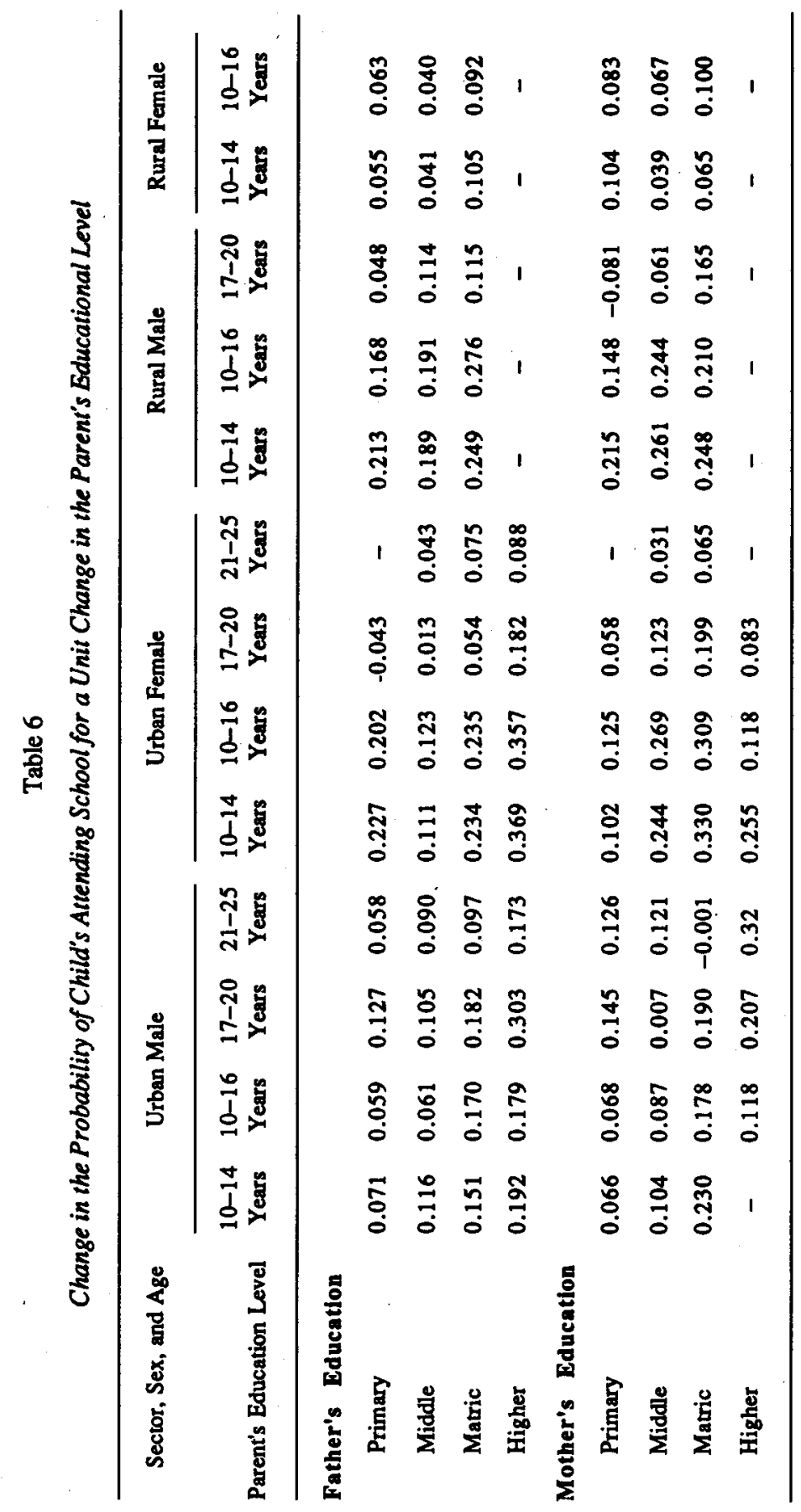


to be greater than that of Primary and Middle.

\section{(v) Father's Tenurial/Employment Status and Occupation}

For the urban households, father's employment status as employer and/or being self-employed is found to be negatively associated with child schooling. The coefficient, however, is significant only for females upto 16 years of age. This suggests that if a person is either self-employed or is an employer, his children, particularly the girls, are less likely to be attending school. This can be partly attributed to the high opportunity cost of schooling perceived by households because of the need for boys' work in the family-based enterprises. In the case of girls, the financial security that a household may feel by owning a business seems to reinforce the cultural-cum-traditional bias against girls' education. It also works against the need to educate the children so as to support the parents in old age. In the case of the rural households, the tenurial status of father being the land-owner is found to have a significant positive influence on child schooling. For Thailand, Mason (1988) has found that the household being a farm-owner has a negative influence on school enrolment.

In general, father's occupation is not found to have any significant impact on child schooling. Except for the clerical and sales and service category, and that also only for boys, the other occupational categories do not appear to be associated with child schooling in any significant manner. A priori, one would expect the professionals and administrative workers to have a higher propensity to invest in human capital formation. Surprisingly, however, the estimates do not show such a pattern. Since the professionals and administrative workers are likely to be relatively more educated and well-paid, it is possible that the influence of this occupational category is partly captured by the income and education variables. ${ }^{26}$ It must also be noted that the occupational categories at the two-digit level mask tremendous variation, wherein, for instance, the primary school teacher is grouped together with an engineer under the category of 'professional'. Hence, the insignificance of the occupation may be partly a reflection of the data limitation.

\section{(vi) Household Labour Force Participation}

Except for urban females, the household's labour force participation behaviour is found to be negatively related to child schooling. This suggests that, for whatever

${ }^{26}$ In most of the cases, with the regressions estimated without the intercept term, the coefficient of father's occupation was found to be significant. For boys upto 16 years of age, the coefficient of each occupational category was positive and significant. In the case of higher aged boys, however, the coefficients were negative and significant. For girls, however, the coefficient of the clerical and production workers was found to be negative and significant in all the cases. The exclusion of income and parents' education did not alter the results in any significant manner. 
reason, if a majority of the other family members are in the labour force, a child is less likely to be attending school. This could be because of the fact that households registering a higher labour force participation either enjoy better prospects in the labour market or this is imposed by the needs. In either case, the opportunity cost of sending children to school is higher than that of the counterpart households registering a lower labour force participation. Table 7 shows that the marginal effect of the household's labour force participation behaviour declines across children's successively higher age groups.

Table 7

Change in the Probability of Child's Attending School for a Unit Change in the Household Labour Force Participation Ratio

Age Group
Sectors/Sex
$.10-14$ Years
$10-16$ Years
17-20 Years
21-25 Years

Urban.

$\begin{array}{lcrrr}\text { Male } & -0.546 & -0.708 & -0.561 & -0.250 \\ \text { Female } & 0.117 & 0.065 & 0.025 & 0.130\end{array}$

Rural

$\begin{array}{lcccc}\text { Male } & -0.611 & -0.582 & -0.123 & - \\ \text { Female } & -0.282 & -0.239 & - & -\end{array}$

\section{(vii) Community Variables}

For the rural households, the literacy level in the village is found to be positively associated with child schooling. This indicates that the households in the villages with a relatively more literate population exhibit a higher level of human capital formation, perhaps reflecting the 'Demonstration or Duesenberry' effect. The marginal effect for females, however, is found to be greater among children of 10-14 years of age and smaller among children of $10-16$ years of age.

Since in the rural sector the age cohorts under analysis are generally enrolled in Middle, Secondary, and College level classes, one would expect a significant positive association between school enrolment and the existence of Middle and High schools in the village. However, the binary variable denoting the existence of a Middle school in 
the village is significant only in the case of boys. ${ }^{27}$ The presence of Primary or High schools in the village hardly appears to matter. For girls the presence of a school, whether Primary, Middle or High, appears to be inconsequential. The non-significance of a 'school in the village' can possibly be attributed to the correlation between some of the explanatory variables, e.g., village literacy and the presence of a school in the village. Exclusion of the 'village literacy' variable from the regression, however, did not improve the significance of the 'school in the village' variables.

\section{CONCLUDING REMARKS}

In addition to the usual caveats regarding the response and non-response errors entailed by the survey data, it needs to be pointed out that the problems such as current enrolment being a censored observation and the issues of joint determination of school enrolment and attainment are not addressed in the foregoing exercise. Given these limitations, the regression results are indicative of the influence of household status, both economic and social, on the propensity to invest in child schooling. A positive association between household income, parental education, and tenurial status as landowner bears out the importance of these factors in shaping the household's decision regarding the investment in human capital formation. The study also finds the traces of the quantity and quality trade-off, which is male-specific.

The most disturbing, though not unexpected, finding of the study appears to be the predominance of the influence originating from parental education. It is this intergenerational transfer of human capital which needs more attention, as it also implies that the illiteracy and, hence, the poverty of parents gets transmitted to the off-spring. Although the literature is replete with rationalization in terms of the efficiency of educated parents in the educational investment of their children, there is reason to believe that this phenomenon of the positive association between parental education and child school-enrolment finds its support from hiring practices in the labour market.

A negative association between father's landlessness and child school-enrolment, after controlling other variables in the equation, alludes to the operation of labour market discrimination. The need to have an in-depth investigation of the labour market processes - and the resultant variation in the rate of return to education across different socio-economic groups - can hardly be over-emphasized in this context. It is expected to yield policy-relevant insights pertaining to the capacity of the individual to participate in the facilities engendered by the system.

${ }^{27}$ The availability of a school in the village or the distance to school has been used to measure the cost of attending school. For the Philippines, King and Lillard (1983) have found that if the mean distance to elementary school is decreased from 0.5 to 0.1 kilometer, the enrolment in the elementary schools will increase by 2.5 percent with favourable repercussions at the High levels. The effect on female enrolment was found to be slightly greater than that on male enrolment. 
Our analysis brings out that labour market hiring practices serve as an important feed-back to the household's human capital formation behaviour. In addition, it provides an explanation of the urban-rural enrolment differentials and the low literacy level. Because the rural labour market cannot absorb the rural educated youth productively, the returns to education are low in the rural sector. On the other hand, the opportunity cost of sending the children to school in the rural areas is higher than that in the urban areas. Finally, our results provide an insight into the male-female differentials in the school enrolment within a given sector. 


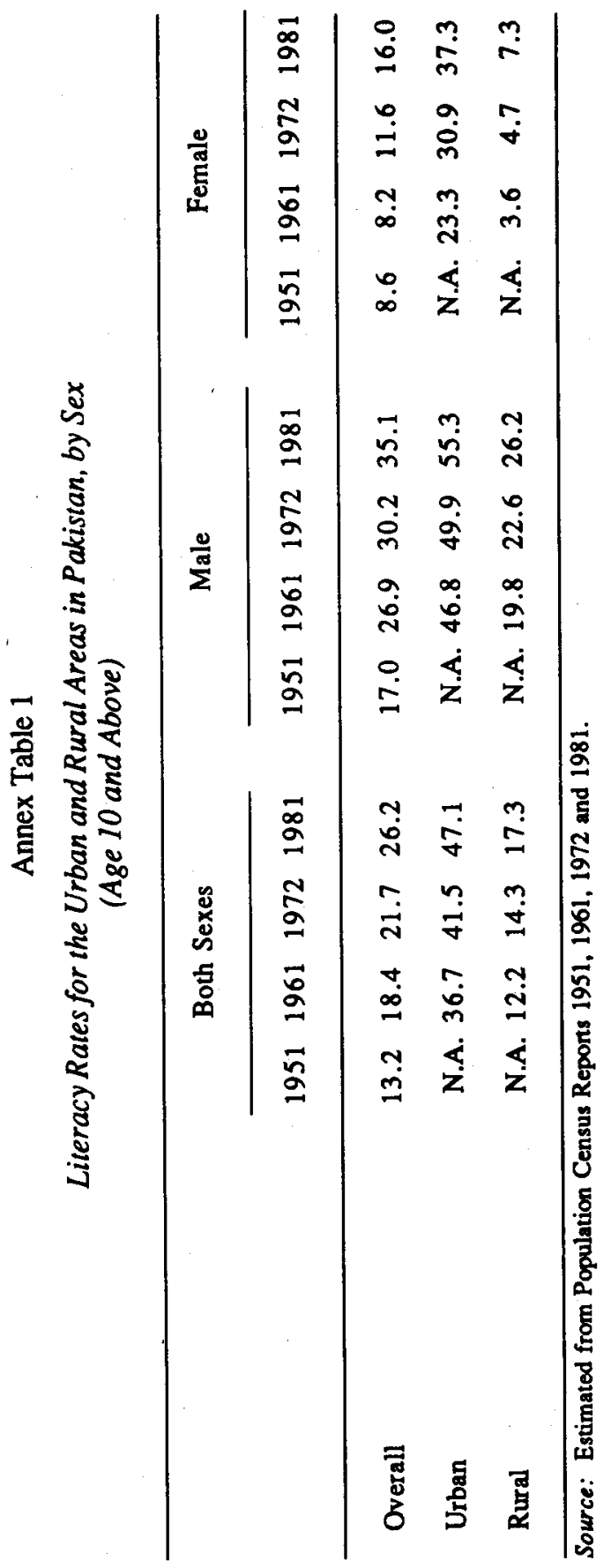




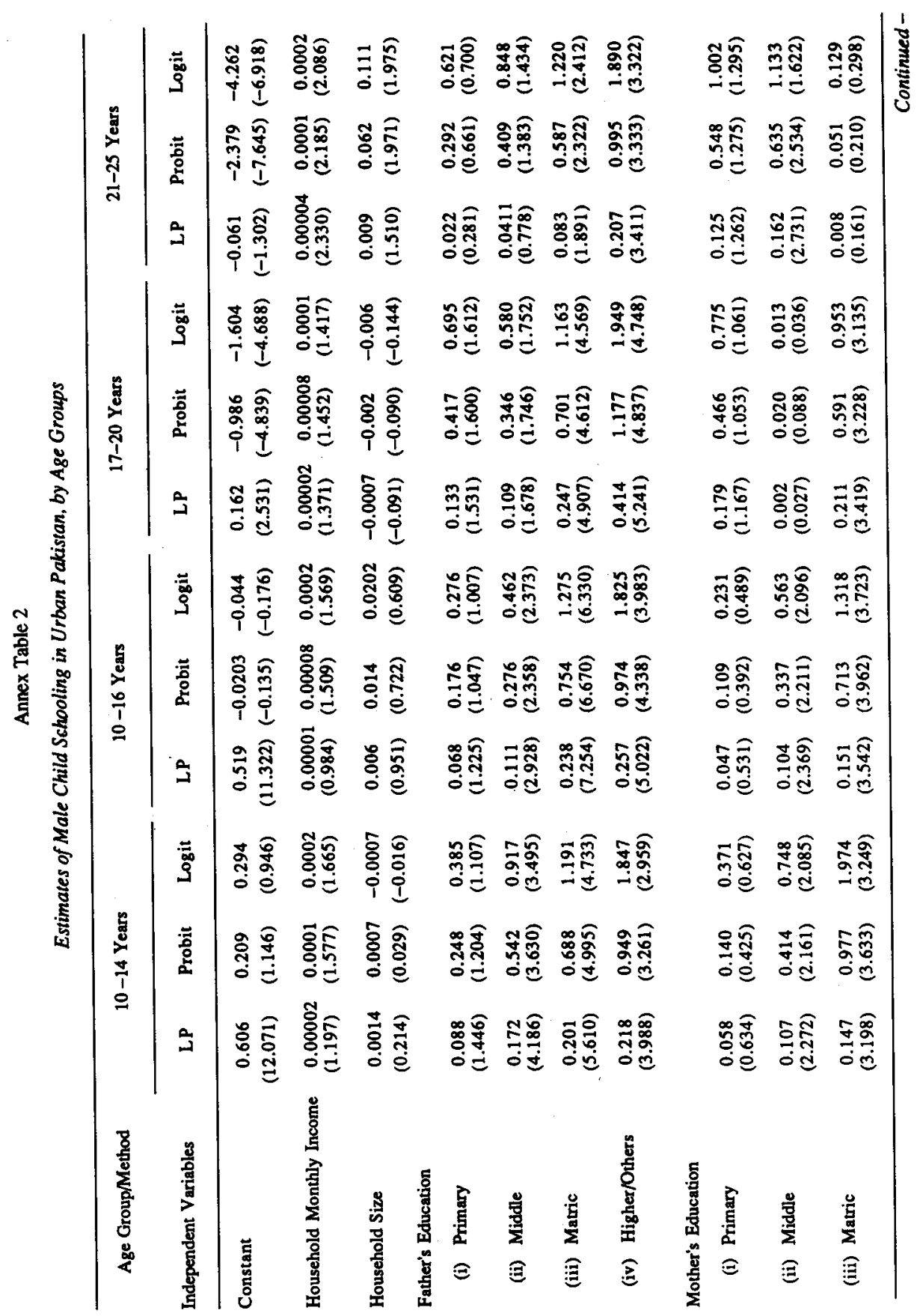




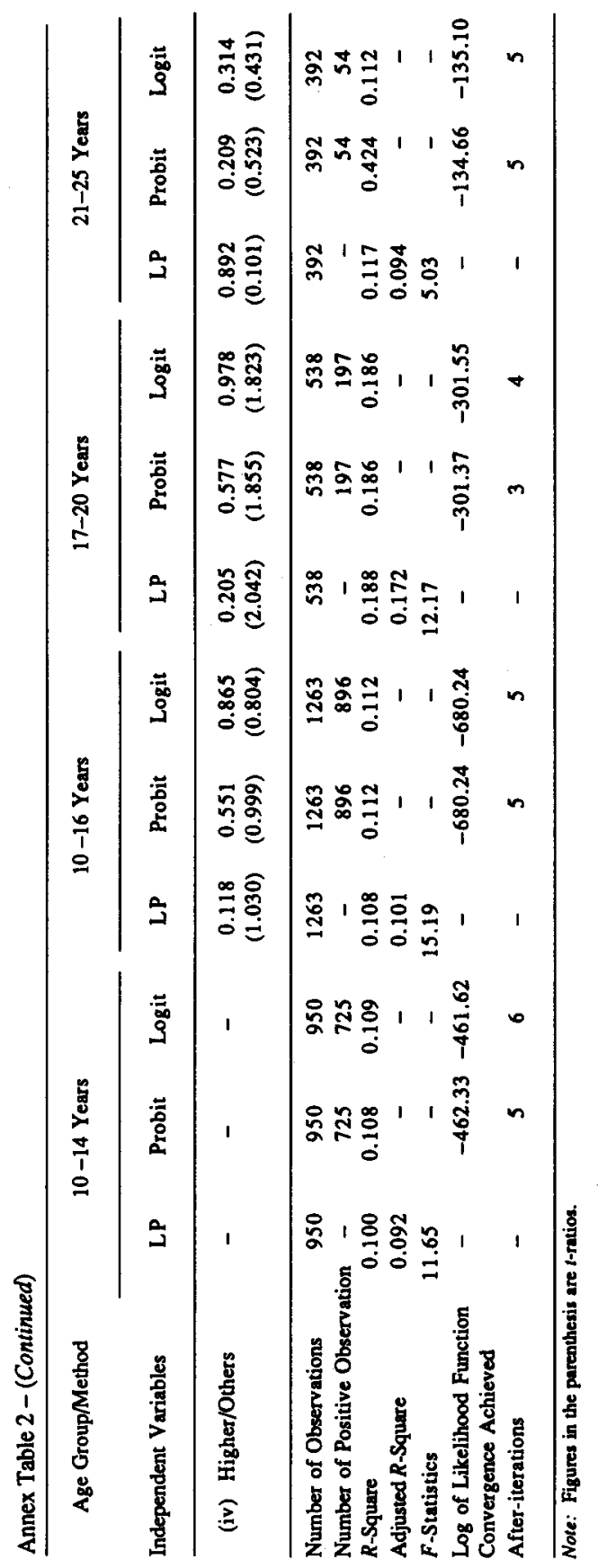




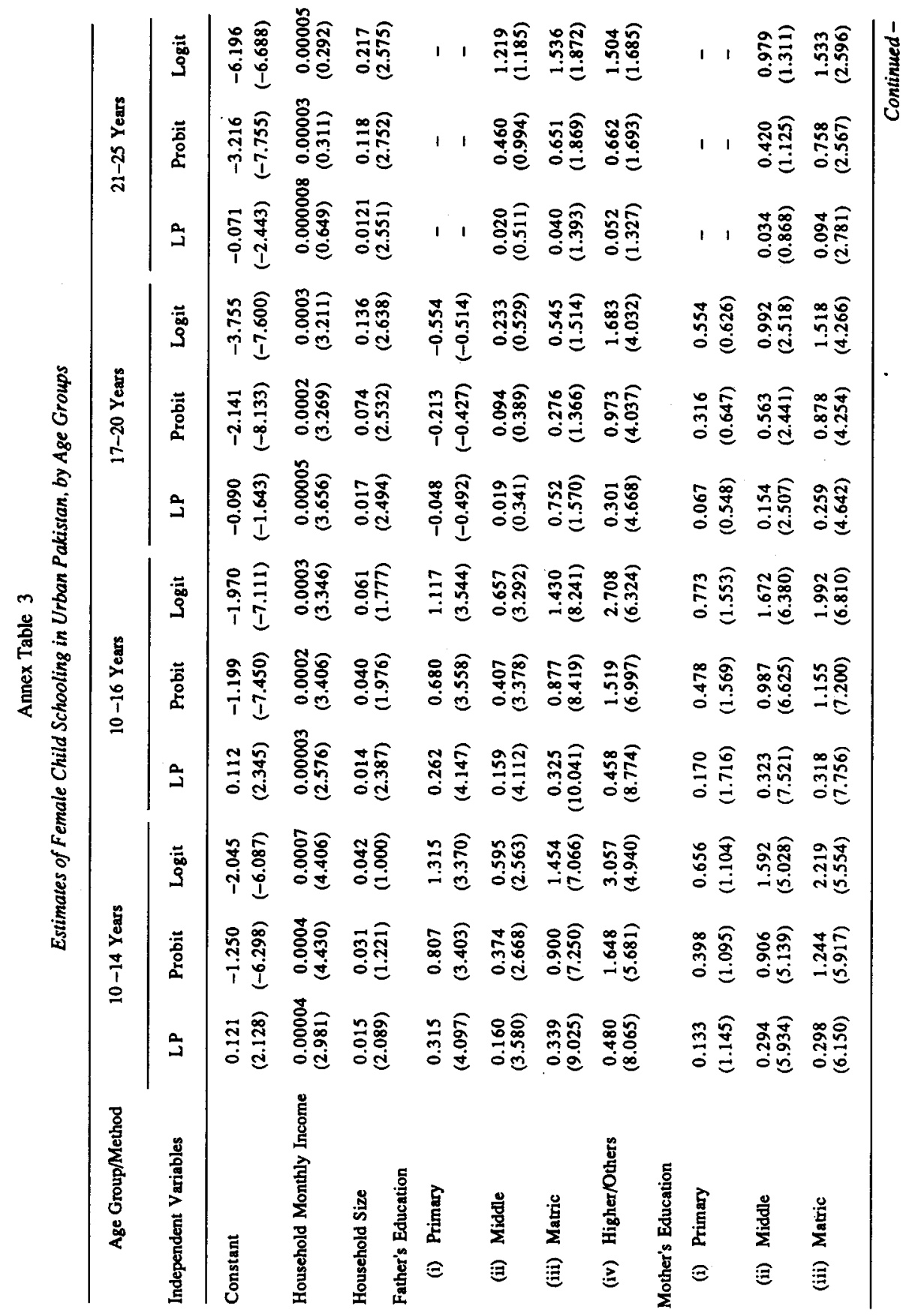




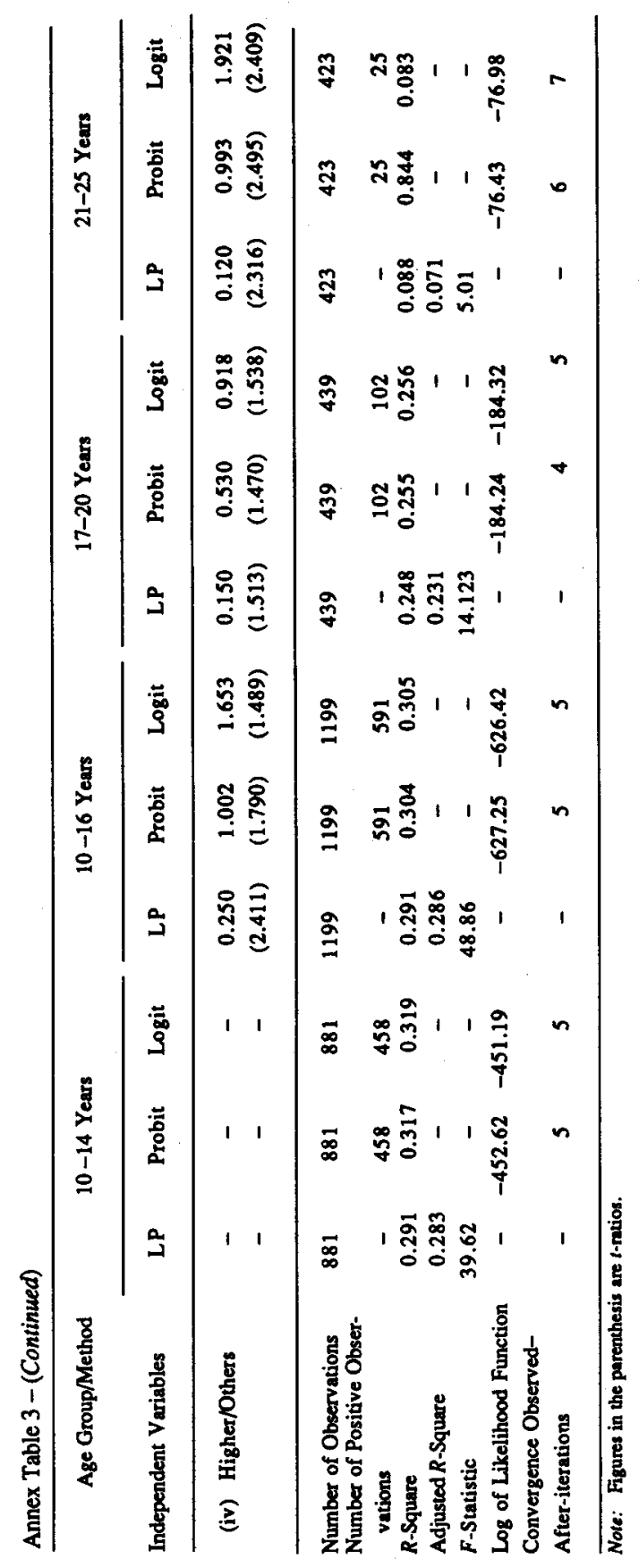




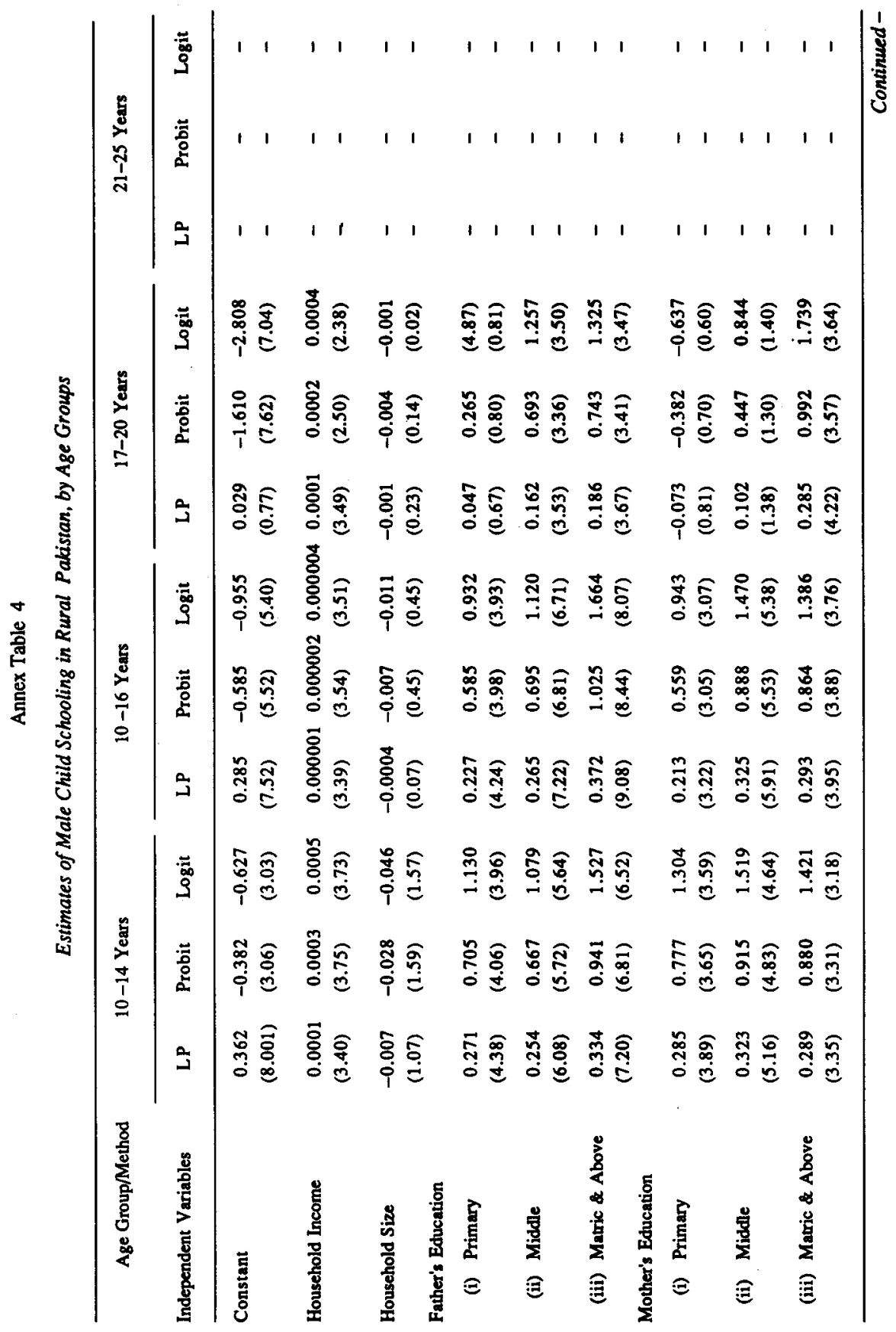




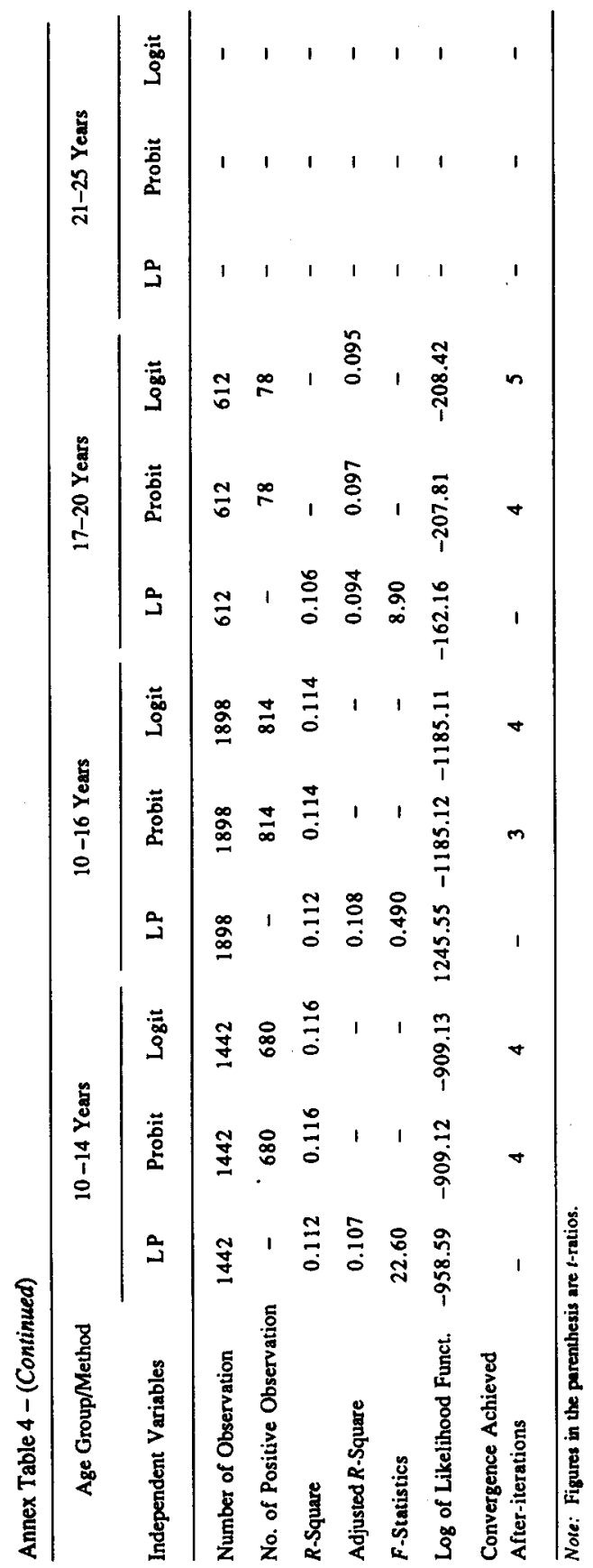




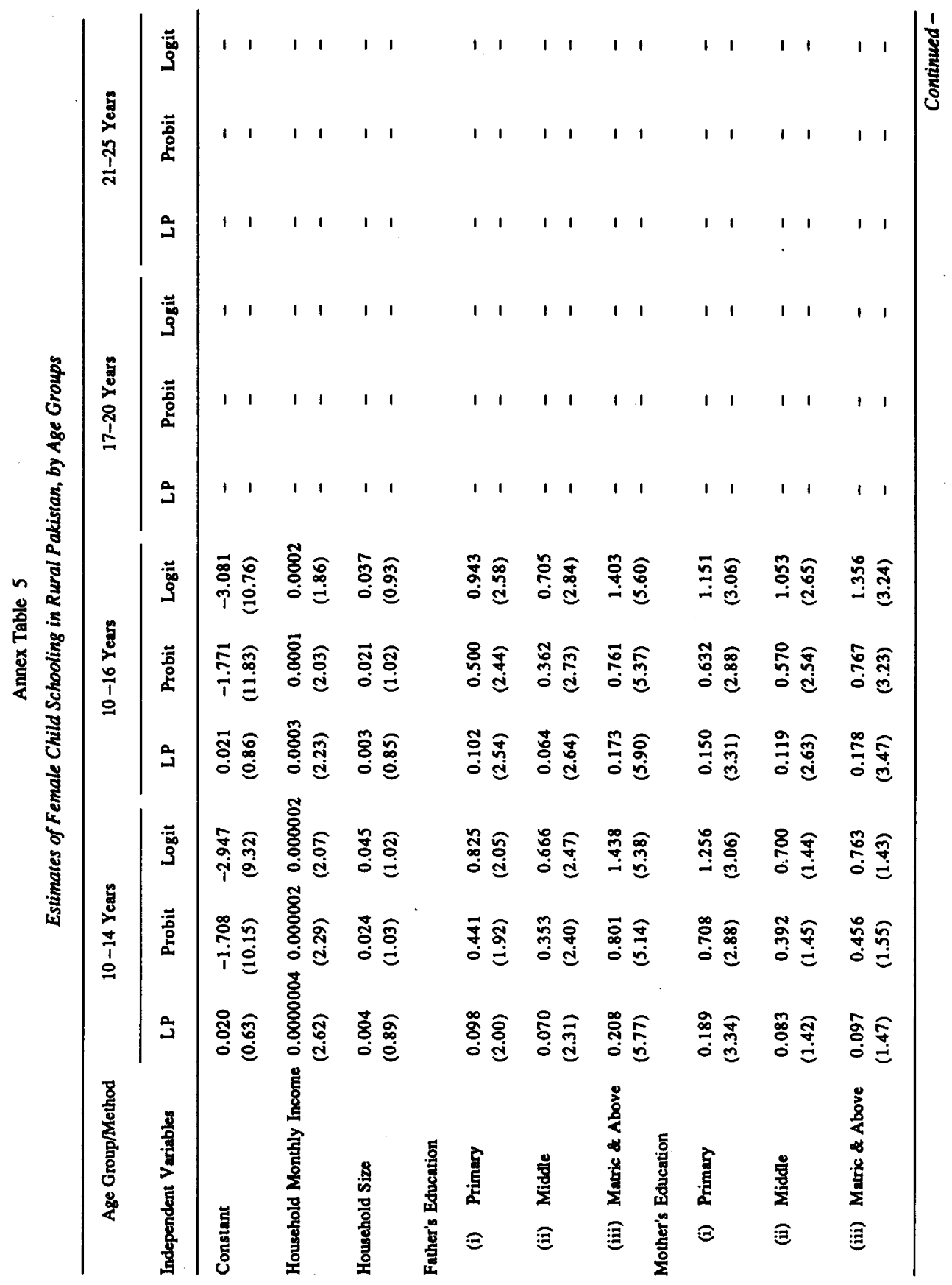




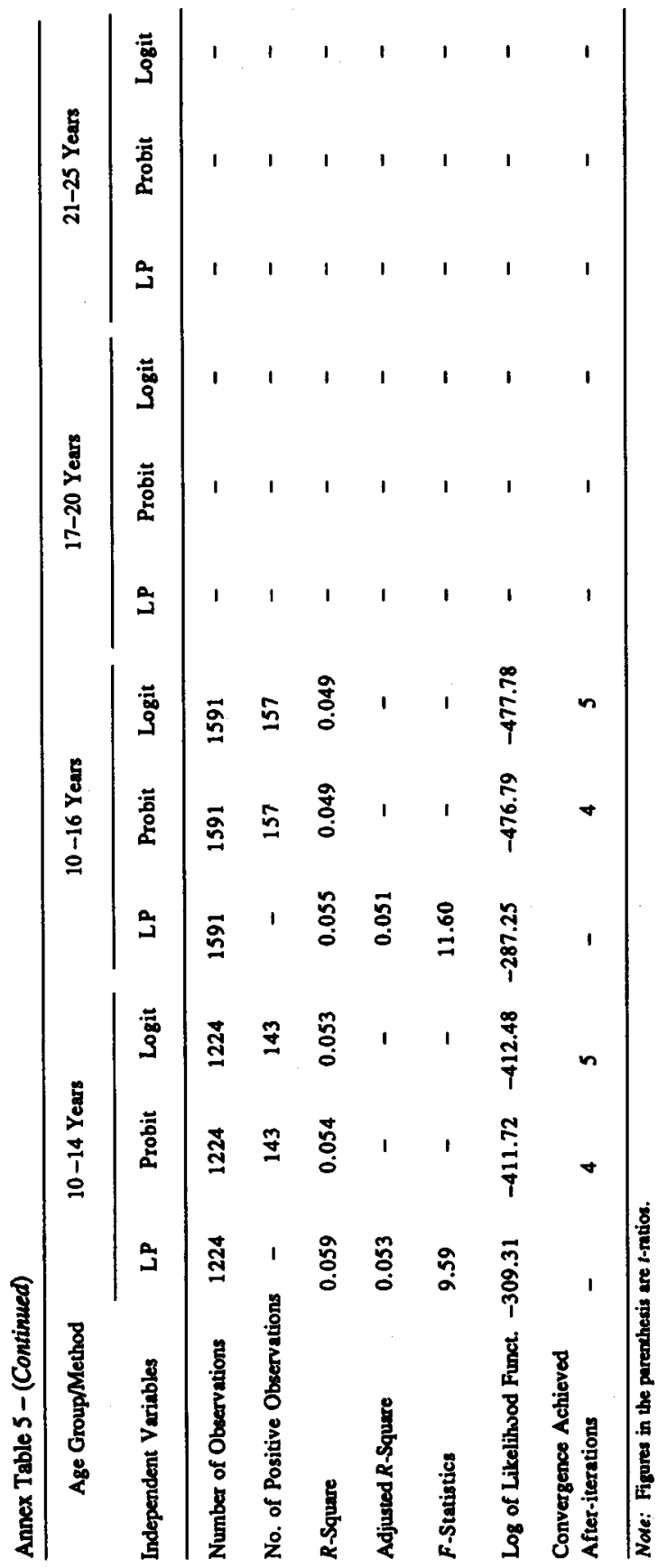




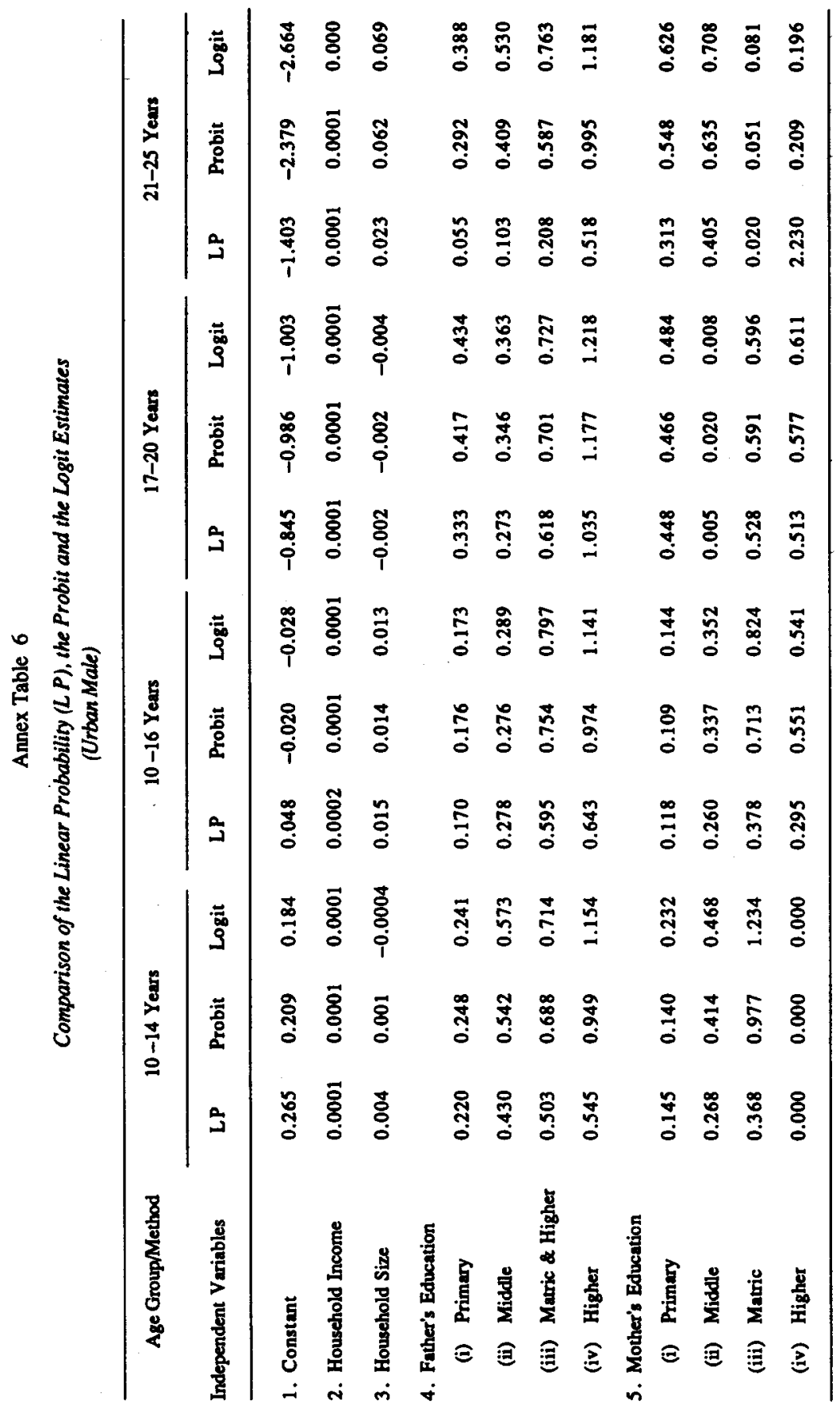




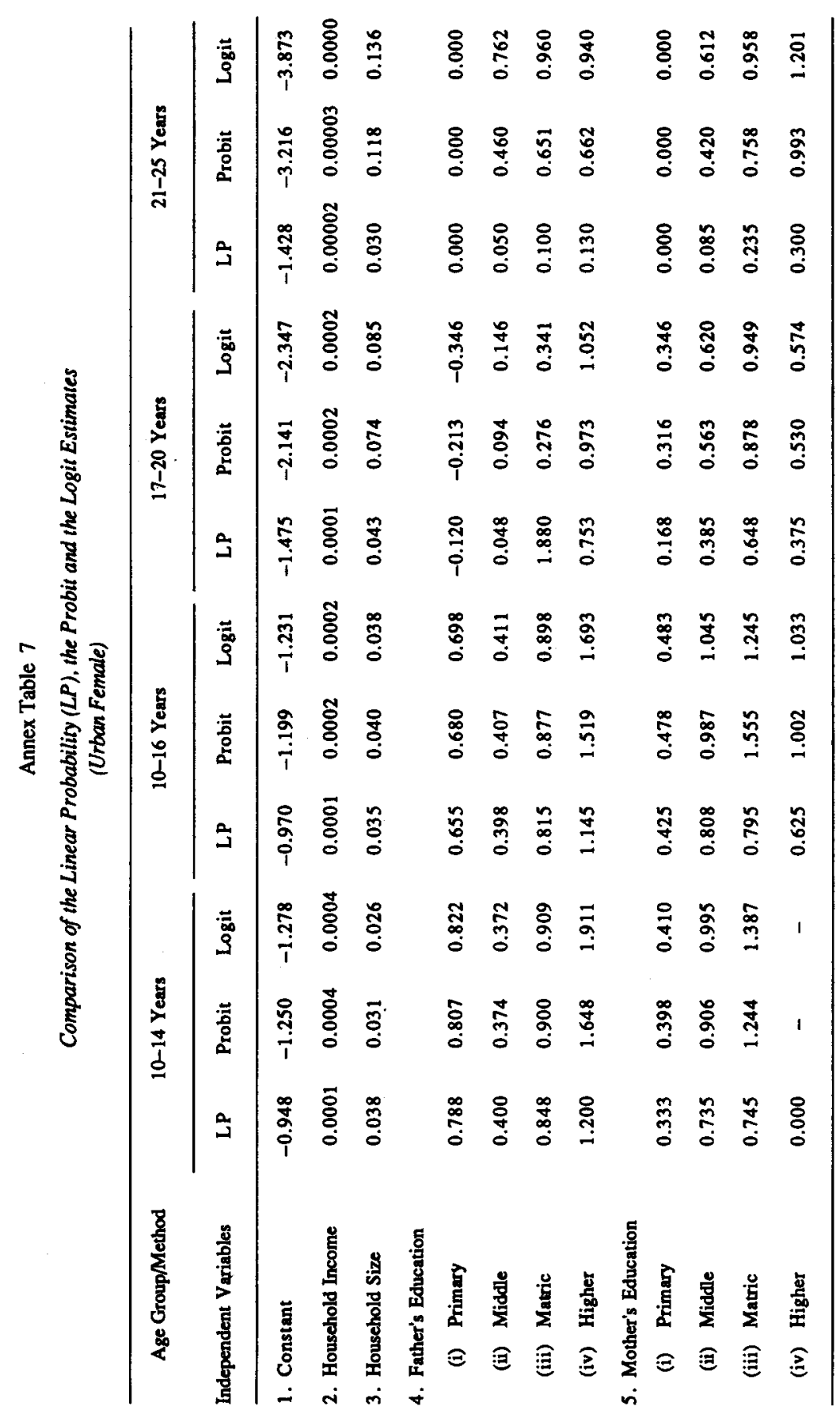




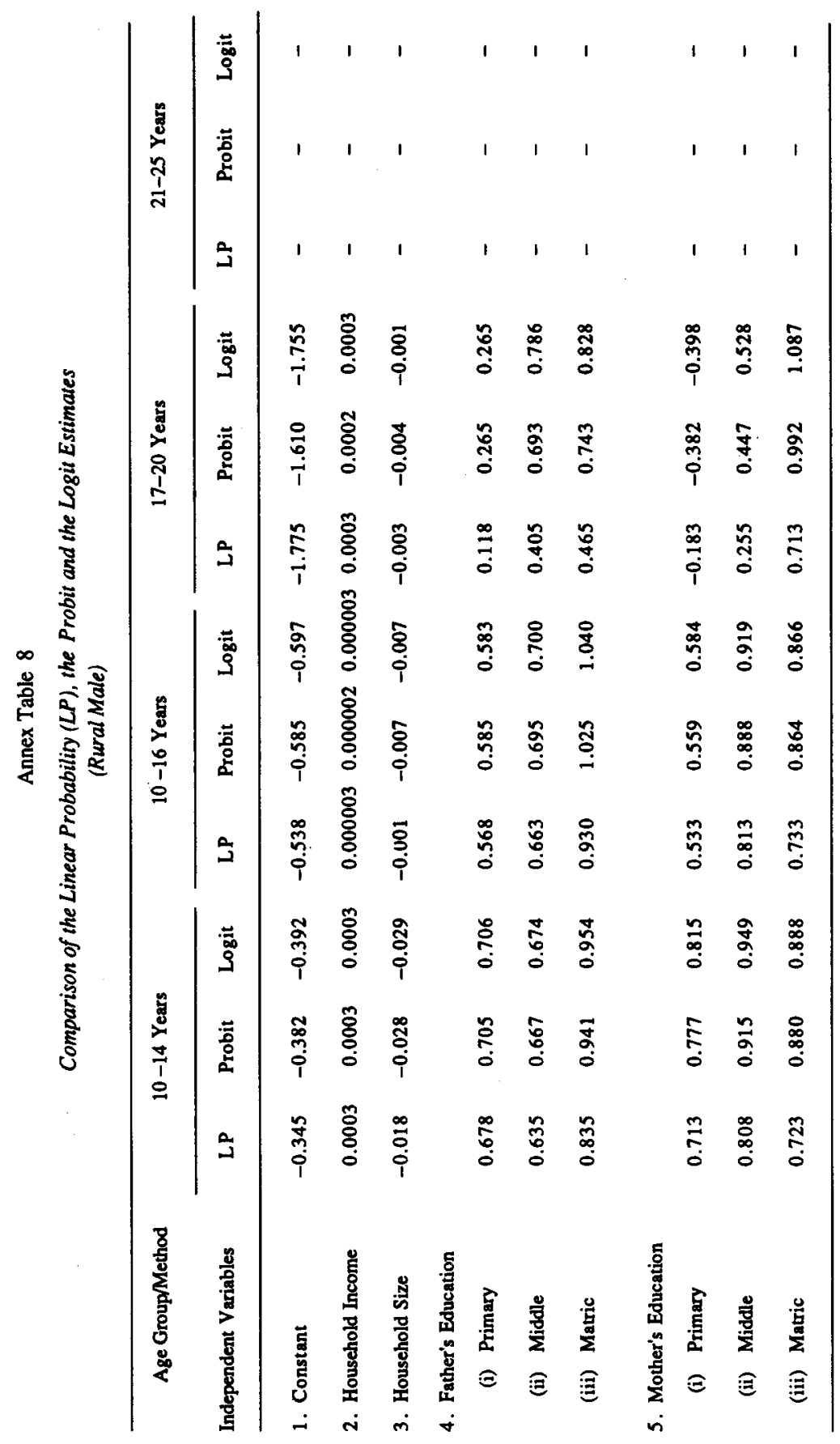




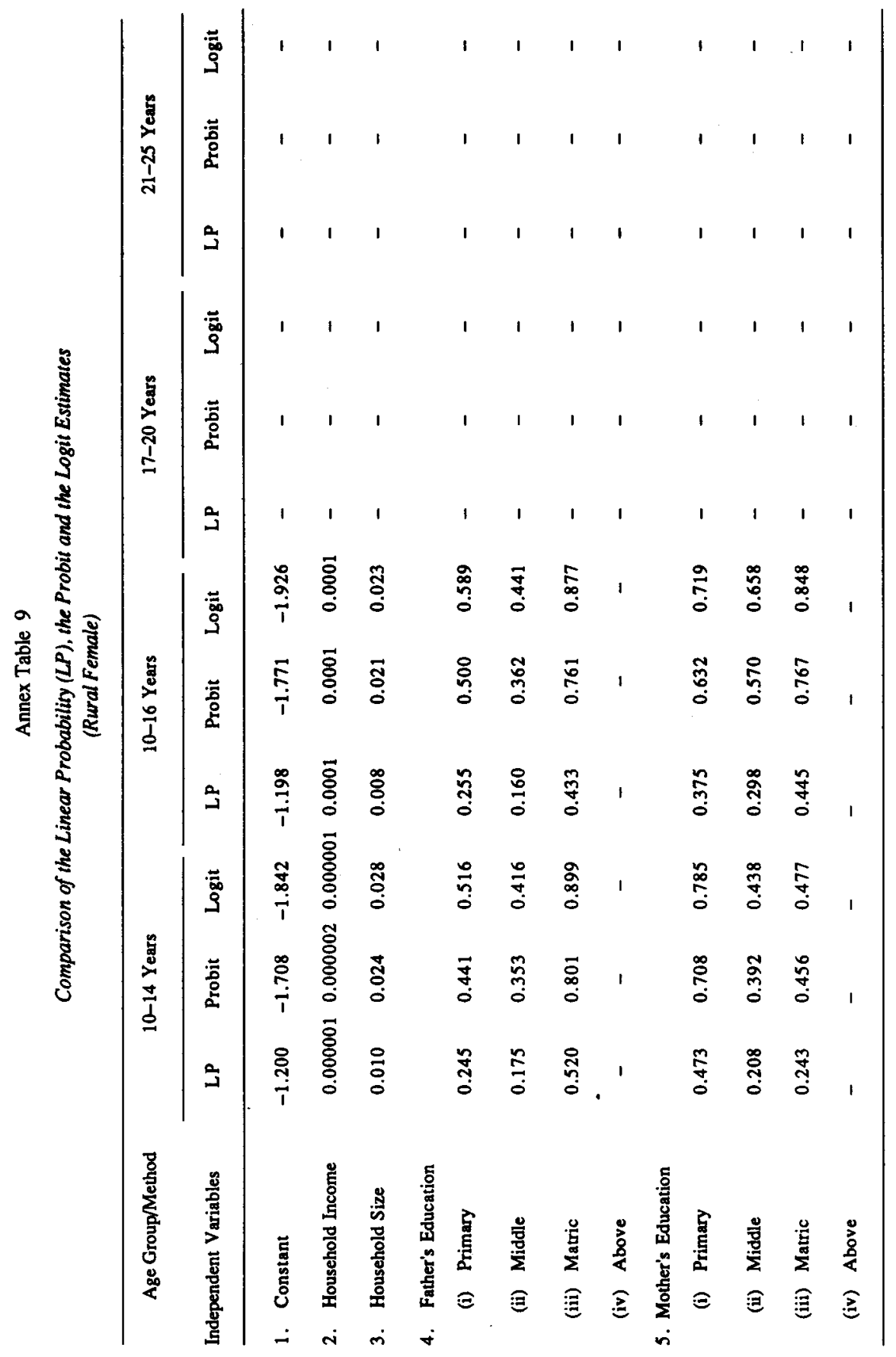




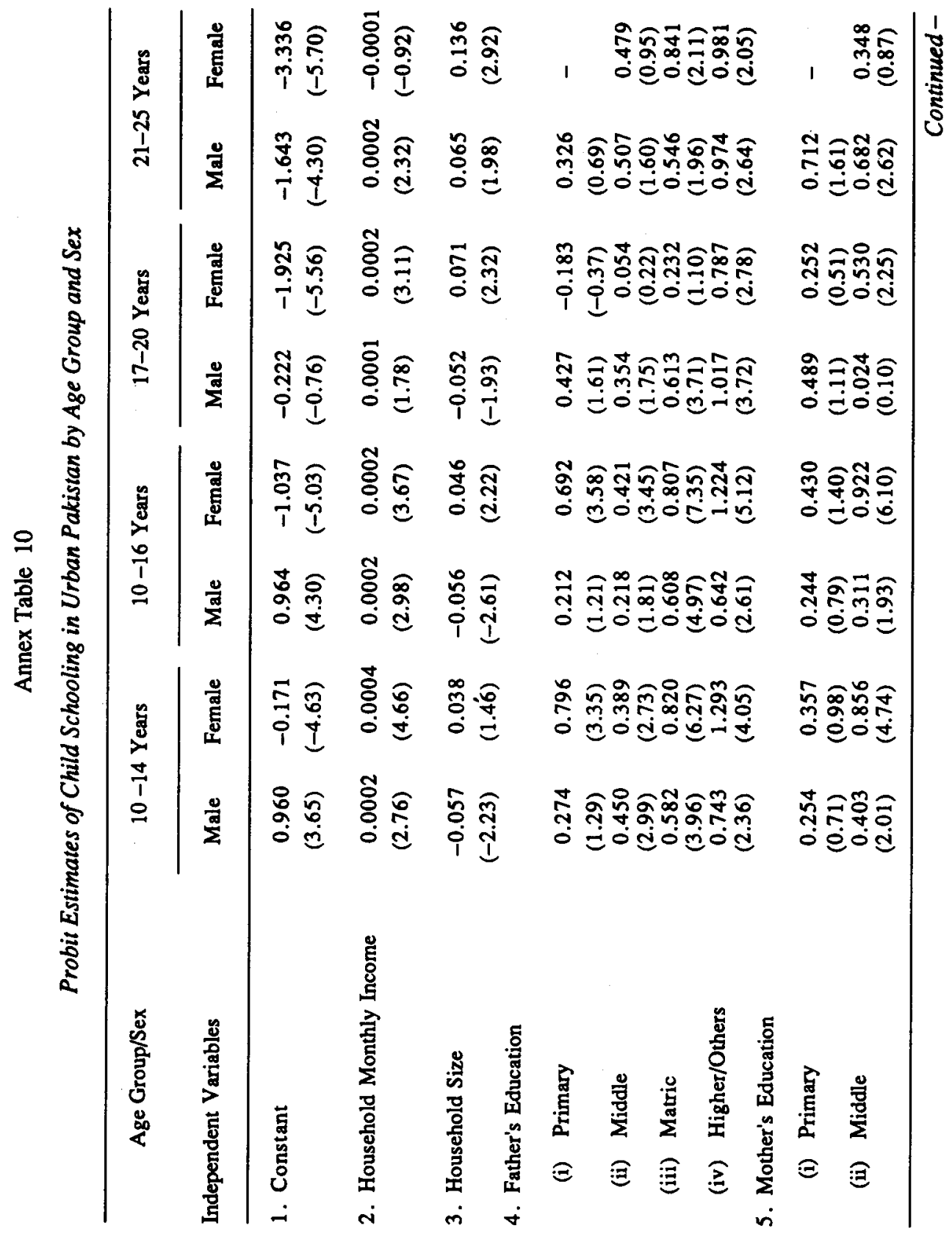




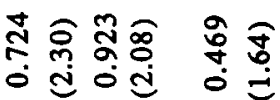

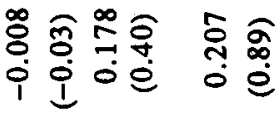

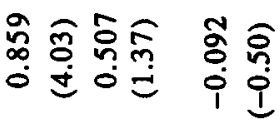

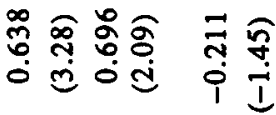

ํํㅇ 융 ㅎํㅇ त

- 00

ติำล

ต ๆ ษ $\div$

$\dot{0} \ddot{0} \dot{0} \dot{i}$

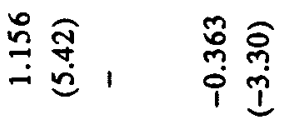

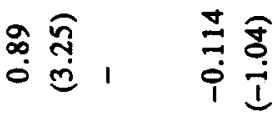

䢓

1

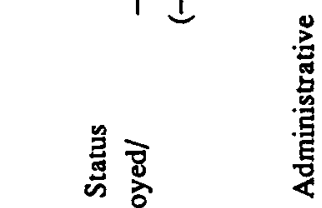

岁 岁 员

-

焉 焉 至

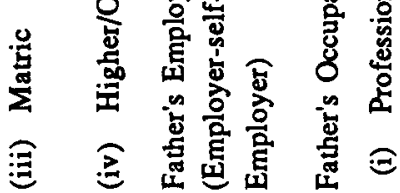

苛 超

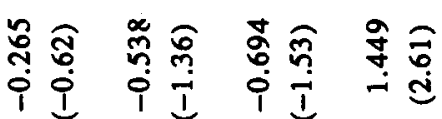

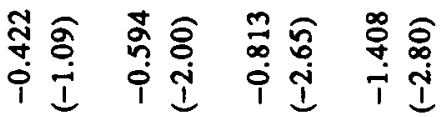

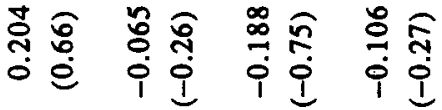

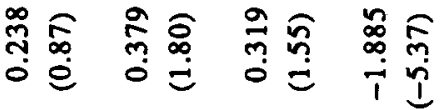

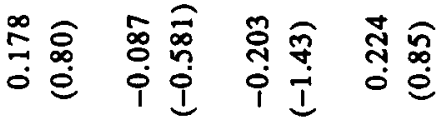

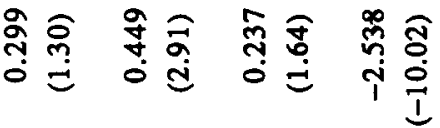

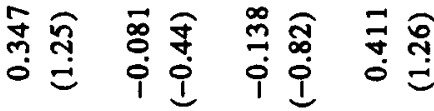

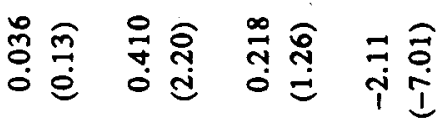

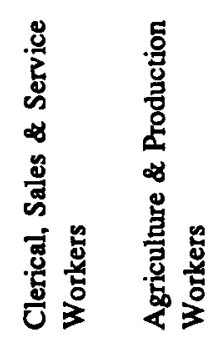

$\exists$

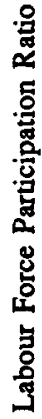

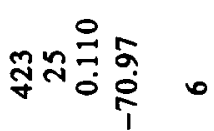

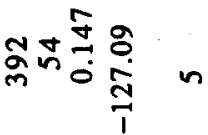

ดํํㅇ ติㅇํㅇ

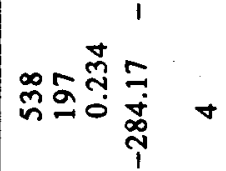

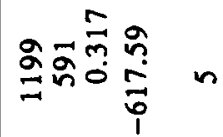

ํㅓㅇㅇㅝ

$\rightarrow \infty \stackrel{m}{m}$

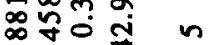

$\infty \forall 0 \frac{\mathbb{Y}}{\mathrm{V}}$

๙ำำ

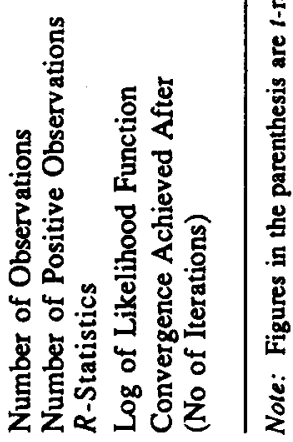




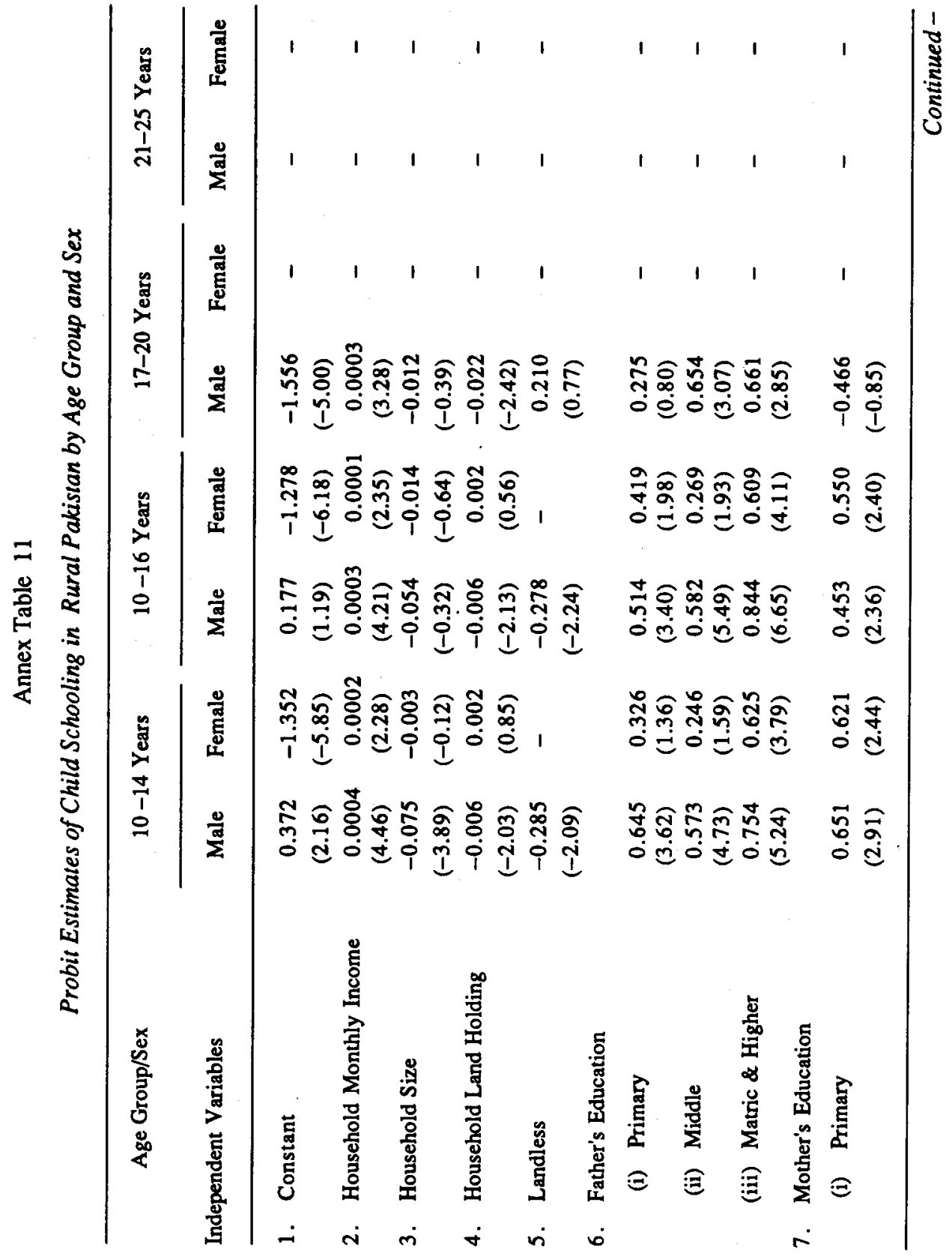




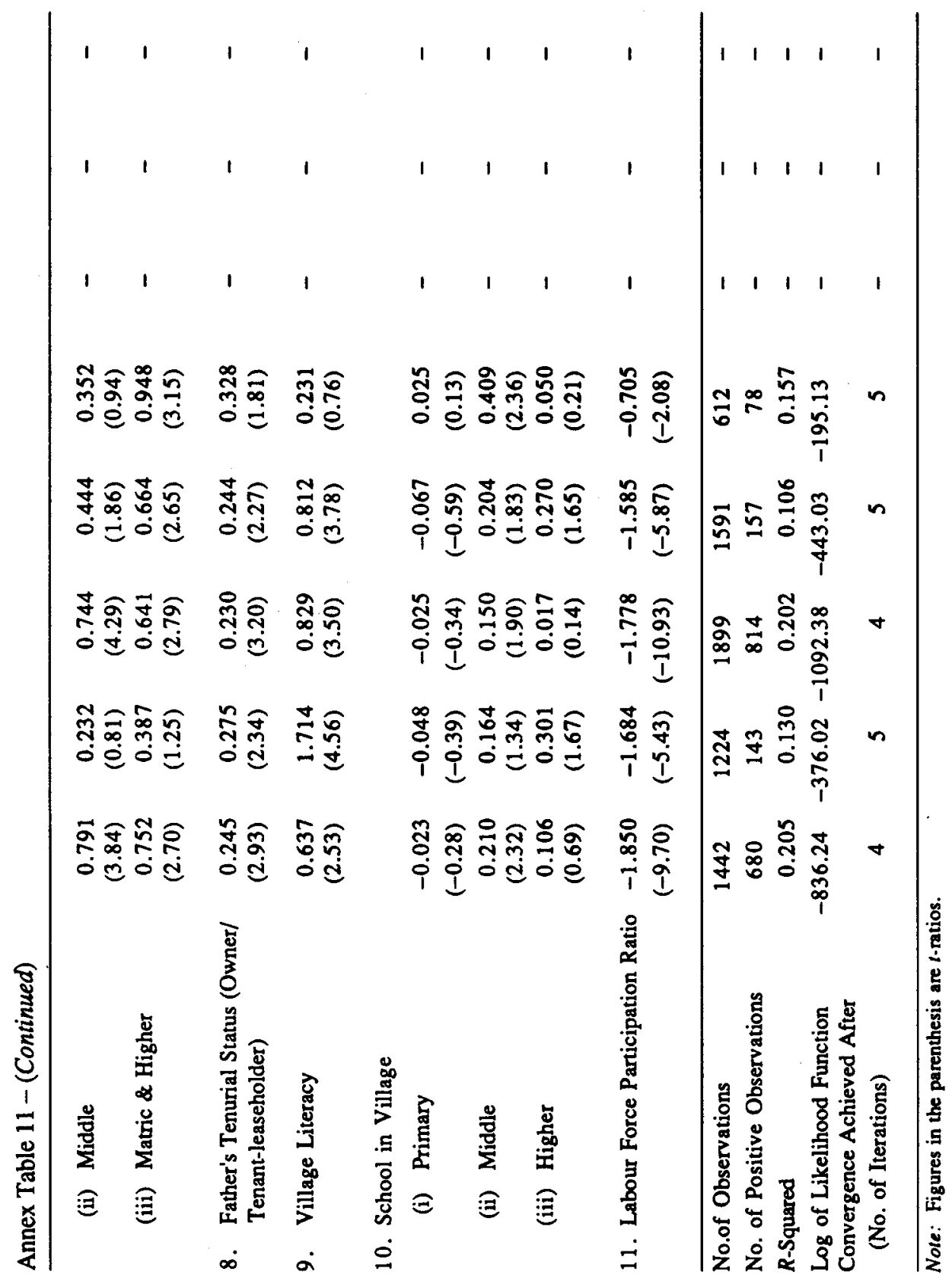




\section{REFERENCES}

Amemiya, T. (1981) Qualitative Response Models: A Survey. Journal of Economic Literature $19: 4$ 483-536.

Becker, G. S., and H. G. Lewis (1973) Interaction Between Quantity and Quality of Children. Journal of Political Economy 81 : 2, Part 2, S279-S288.

Becker, G. S., and N. Tomes (1976) Child Endowments and the Quantity and Quality of Children. Journal of Political Economy 84 : 4, Part 2, S143-S162.

Behrman, J., and B. L. Wolfe (1984) A More General Approach to Fertility Determination in a Developing Country: The Importance of Biological Supply Considerations, Endogenous Tastes, and Unperceived Jointness. Economica 51 : 203 319-339.

Birdsall, N. (1980) A Cost of Siblings: Child Schooling in Urban Colombia. Research in Population Economics 2 115-150.

Blake, Judith (1981) Family Size and the Quality of Children. Demography 18 : $4421-$ 442.

DeTray, D: (1973) Child Quality and the Demand for Children. Journal of Political Economy 81 : 2, Part 2, S570-S595.

DeTray, D. (1978) Child Schooling and Family Size: An Economic Analysis. The Rand Corporation, R-2301-NICHD. Santa Monica, California.

DeTray,D.(1983) Children's Economic Contributions in Peninsular Malaysia. The Rand Corporation. N-1839-AID. Santa Monica, California.

Duesenberry, J. S. (1952) Income, Saving, and the Theory of Consumer Behaviour. Cambridge, M A: Harvard University Press.

Goldberger, A. S. (1964) Econometric Theory. New York: John Wiley.

Goldfeld, S. M., and R. E. Quandt (1972) Non-linear Methods in Econometrics. Amsterdam: North-Holland.

Harrison, D. (1980) Household Decisions about Fertility and Children's Education: The Case of Malaysia. Unpublished Ph.D. dissertation, UCLA.

Irfan, M. (1985) Poverty and Household Demographic Behaviour in Pakistan - Insights from PLM Survey 1979. PLM Project Report No. 11. Pakistan Institute of Development Economics, Islamabad.

Khan, S. R., and M. Irfan (1985) Rates of Return to Education and the Determinants to Earnings in Pakistan. The Pakistan Development Review $34: 3$ \& 4.

King, E. M., and L. A. Lillard (1983) Determinants of Schooling Attainment and Enrolment Rates in the Philippines. The Rand Corporation. N-1962-AID. Santa Monica, California.

Kmenta, J. (1986) Elements of Econometrics. New York: Macmillan.

Lindert, P. (1977) Sibling Position and Achievement. Journal of Human Resources 12 : 2 198-219.

Maddala, G. S. (1983) Limited-Dependent and Qualitative Variables in Econometrics. Cambridge: Cambridge University Press. 
Mason, A. (1988) The Transition in Education: Inter-generationalEffects.Research Paper Series No. 42, Nihon University, Population Research Institute, Tokyo, Japan. Rosenzweig, M. (1978) The Value of Children's Time, Family Size, and Non-Household Child Activities in a Developing Country: Evidence from Household Data. Research in Population Economics 1 : 331-347.

Rosenzweig, M., and K. Wolpin (1980) Testing the Quantity-Quality Fertility Model: The Use of Twins as a Natural Experiment. Econometrica $4: 1$ 227-240.

Waite, L. J., D. DeTray and R. Rindfuss (1983) Expectations of Malaysian Mothers for the Schooling of Their Children. The Rand Corporation. N-1947-AID, Santa Monica, California.

Wolfe, B. L., and J. R. Behrman (1983) Child Quantity and Quality in a Developing Country: The Importance of Family Background, Endogenous Tastes, and Biological Supply Factors. University of Pennsylvania, Philadelphia, Pennsylvania. 